\title{
Influence of solar forcing, climate variability and modes of low-frequency atmospheric variability on summer floods in Switzerland
}

\author{
J. C. Peña ${ }^{1}$, L. Schulte ${ }^{2}$, A. Badoux ${ }^{3}$, M. Barriendos ${ }^{4}$, and A. Barrera-Escoda ${ }^{1}$ \\ ${ }^{1}$ Meteorological Service of Catalonia, Barcelona, Spain \\ ${ }^{2}$ Department of Physical and Regional Geography and ICREA, University of Barcelona, Barcelona, Spain \\ ${ }^{3}$ Mountain Hydrology and Mass Movements Research unit, Swiss Federal Institute for Forest, Snow and Landscape Research \\ WSL, Birmensdorf, Switzerland \\ ${ }^{4}$ Catalan Institute of Climate Sciences (IC3) and Department of Modern History, University of Barcelona, Barcelona, Spain
}

Correspondence to: L. Schulte (schulte@ub.edu)

Received: 2 December 2014 - Published in Hydrol. Earth Syst. Sci. Discuss.: 19 December 2014

Revised: 5 May 2015 - Accepted: 20 August 2015 - Published: 10 September 2015

\begin{abstract}
The higher frequency of severe flood events in Switzerland in recent decades has given fresh impetus to the study of flood patterns and their possible forcing mechanisms, particularly in mountain environments. This paper presents a new index of summer flood damage that considers severe and catastrophic summer floods in Switzerland between 1800 and 2009, and explores the influence of external forcings on flood frequencies. In addition, links between floods and low-frequency atmospheric variability patterns are examined. The flood damage index provides evidence that the 1817-1851, 1881-1927, 1977-1990 and 2005-present flood clusters occur mostly in phase with palaeoclimate proxies. The cross-spectral analysis documents that the periodicities detected in the coherency and phase spectra of 11 (Schwabe cycle) and 104 years (Gleissberg cycle) are related to a high frequency of flooding and solar activity minima, whereas the 22-year cyclicity detected (Hale cycle) is associated with solar activity maxima and a decrease in flood frequency. The analysis of low-frequency atmospheric variability modes shows that Switzerland lies close to the border of the principal summer mode. The Swiss river catchments situated on the centre and southern flank of the Alps are affected by atmospherically unstable areas defined by the positive phase of the pattern, while those basins located in the northern slope of the Alps are predominantly associated with the negative phase of the pattern. Furthermore, a change in the low-frequency atmospheric variability pattern related to the major floods occurred over the period from 1800 to 2009;
\end{abstract}

the summer principal mode persists in the negative phase during the last cool pulses of the Little Ice Age (1817-1851 and 1881-1927 flood clusters), whereas the positive phases of the mode prevail during the warmer climate of the last 4 decades (flood clusters from 1977 to present).

\section{Introduction}

The response of floods to global changes is complex and can vary on a regional scale. Extreme flood event frequency can be highly sensitive to modest environmental and climate changes (Knox, 2000), so much so, in fact, that these changes might not be recorded by mean hydrological values but rather by a changing pattern in the magnitude and frequency of extreme events (Benito et al., 2005). Moreover, these changes often occur during transitional stages of climatic pulses (Knox, 2000; Glaser and Stangl, 2004; Schulte et al., 2009a) and may respond to complex exogenic, endogenic and autogenic climate forcing mechanisms (Versteegh, 2005). Yet, the debate concerning the factors and trends that might influence flood dynamics, such as the rise in temperature, river management and other human activities, remains a controversial one (Brázdil et al., 2006).

In high mountain catchments, major flood events are determined by the intensity and frequency of extreme precipitation events, high discharge rates provoked by the melting 
of glacial ice and snow cover, the outburst flood of lakes dammed by landslides as well as by other phenomena. The Alps are highly sensitive to changes in atmospheric circulation and environmental perturbations that influence the hydrological regime and flooding patterns reconstructed from instrumental data and documentary sources (Hächler-Tanner, 1991; Röthlisberger, 1991; Gees, 1997; Pfister, 1999; Luterbacher et al., 2004; Weingartner and Reist, 2004; ALP-IMP, 2006; Burger, 2008; Schmocker-Fackel and Naef, 2010a, b; Wetter et al., 2011) and, regarding longer time series, from natural proxies such as lacustrine records, glaciers, dendrochronology and isotopic studies of speleothems (Tinner et al., 2003; Casty et al., 2005; Holzhauser et al., 2005; Boch and Spötl, 2008; Wilhelm et al., 2012). Referring to the last three millennia, solar activity may be an important driver of alpine floods as indicated by the periodicities (Gleissberg solar cycles) of geochemical and pollen proxies of alluvial plain sediments in the Swiss Alps (Schulte et al., 2008, 2015) and by their correlation with climate proxies.

During the last 500 years, periods of large floods have been reported by detailed documentary inventories and instrumental series compiled by Röthlisberger (1991), HächlerTanner (1991), Gees (1997), Pfister (1999), Lehmann and Naef (2003), Vischer (2003), Burger (2008) and Hilker et al. (2009). According to the annual number of floods used by Schmocker-Fackel and Naef $(2010 \mathrm{a}, \mathrm{b})$ as a parameter for the evaluation of the climate and hydric variability of catchments in Switzerland, increased flooding occurred during four main periods: $1560-1590,1740-1790,1820-1940$ and 1970-2007. Since the second half of the 19th century, river correction and embankment may have influenced the frequency of flooding in the Swiss catchments. Other studies discuss the possible links between hydrological extreme events and low-frequency atmospheric variability patterns (Pfister, 1999; Jacobeit et al., 2006; Knox, 2000; Glaser and Stangl, 2004; Mudelsee et al., 2004; Schmocker-Fackel and Naef, 2010b; Wilhelm et al., 2012), such as the North Atlantic Oscillation. However, in the Swiss Alps, floods show a strong seasonal distribution recording highest frequencies during the summer months. Summer climate in the North Atlantic-European sector possesses a principal pattern of year-to-year variability which is defined as the main empirical orthogonal function (EOF1) of the standardized anomalies of the European mean sea level pressure (EMSLP) during July and August. The location of the action centres shows strong positive anomalies (high pressure centre) between the Scandinavia Peninsula and Great Britain, while the Mediterranean region is dominated by light negative anomalies (low pressure centre). The EOF1 exerts a strong influence on rainfall, temperature and cloud cover through changes in the position of storm tracks in the North Atlantic region (Folland et al., 2009), but also in many areas of southern Europe (Bladé et al., 2011).

Our study aims to investigate the possible links between flood frequency in Switzerland and solar forcing, volcanic eruptions, climate variability and the North Atlantic dynamics over the last two centuries. A study of summer flood frequencies in Switzerland has been conducted for the period 1800-2009, based on the calculation of a flood damage index (henceforth INU) from existing flood inventories for Switzerland, summarizing both the severity of these events and their spatial extent. Special attention will be focused also on the possible different evolution between flood dynamics at the northern and southern slopes of the Alps during the last two centuries. The influence of solar forcing on flood frequencies is investigated, applying a cross-spectral analysis to the sunspot record and INU to determine the common periodicities, and we used temperature reconstructions, volcanic eruptions, beryllium-10 records (solar activity) and oxygen isotope data (Greenland climate proxies) for finding links. Finally, the analysis of the possible links between floods and North Atlantic dynamics is focused on the low-frequency atmospheric variability pattern (EOF1).

\section{Data and methods}

\subsection{Historical flood data}

Historical descriptions of flood events are reported in the Alps by local monographies, chronicles, Council minutes, manuscript sources and specialized literature, and from the 18th century onwards, by press and expert reports (Pfister, 1999). Instrumental discharge measurements of gauge stations started in Switzerland mostly at the beginning of the 20th century.

To explain the variability and frequency of floods in Switzerland between 1800 and 2009, an integrated flood damage index (INU) was calculated from two data sources: a flood database, provided by Gees (1997) for the period 18001994, which were developed from the historical records compiled by Röthlisberger (1991), Pfister and Hächler (1991) and further historical investigation; and selected flood damage data extracted from the Swiss flood and landslide damage database of the Swiss Federal Institute for Forest, Snow and Landscape Research, WSL for the period 1972-2009 (Hilker et al., 2009). The contemporary flood series of the WSL, generated from damage events reported by the local, regional and national press and websites (police, fire department, etc.), were transformed according to the database structure of Gees (1997) to extend the flood index.

Both sources (Gees, 1997 and WSL) report the flood damage expressed by the equivalent of present economic loss. In general, the information included in the database is structured as follows: the municipality, river or canton affected by the hazard, the date, the type of process (flood, debris flow, landslide or rockfall), the triggering weather conditions and a description of the damage, including the number of people affected, killed and injured (Hilker et al., 2009). However, the INU considers only flooding, floods and debris flows. 
Based on this information, we built a database with a matrix structure, $\mathbf{A}(M \times N)$, where $M$ rows state the event date and each of the $N$ columns reports the flood information for each of the Swiss cantons. The cells from which the matrix is comprised then either bear a code or are left empty, depending on the incidence of a flood event on the given date and in the specific canton. The code reports the flood category, based on the damage in Switzerland quantified in millions of Swiss francs (CHF) taking inflation into account (Gees, 1997; Hilker et al., 2009). A flood is considered a low-damage event (L) if the damage is calculated at less than CHF 0.2 million; a medium-damage event (M) if the damage is between 0.2 and 2 million; a severe-damage event (S) if the damage is between 2 and 20 million; a very severe-damage event (VS) if the damage is between 20 and 100 million; and a catastrophic-damage event (C) when the damage caused by the flood event exceeds CHF 100 million.

Difficulties with regard to the homogeneity of historical flood time series are expected due to the lower precision and possible data gaps of flood records from earlier periods. However, Gees (1997) showed that this heterogeneity mostly affects the small and medium category floods, whereas the very severe and catastrophic events have not shown this effect since the increased sensibility of the population caused by the increased floods during the first half of the 19th century, the application of the Swiss Federal Law on River Correction since 1854 and the improved information transmission by the press. Moreover, flood mitigation management such as levee construction, retention reservoirs and river detour into large lakes may have had an influence on flood frequency since the 18th century and improved since 1900 (Wetter et al., 2011). Other factors such as ground sealing, canalizing riverbeds and exposure of public infrastructure increased runoff, discharge and economic losses during the 20th century. It is difficult to estimate how these opposite effects partially compensate for each other (Pfister, 1999). It is important to state that the improved river regulation in Switzerland, conducted from 1850 onwards, may mitigate the damage caused by low, medium and major floods, but cannot prevent completely the total impact of category VS and C floods as occurred for example during the 1987 and 2005 events. From our research on flood dynamics and evolution of delta morphology of the Lütschine and Hasli Aare rivers starting from 1480 (Schulte et al., 2015), we observe the same trend: the frequency of very severe and catastrophic floods does not show a substantial change, whereas small and medium floods are recorded with improved precision after 1800. Therefore, we use only the very severe (VS) and catastrophic (C) flood events to generate the flood damage index (INU). To validate the historical flood data, in order to build the INU index, all events of category VS and C were checked if they were cited by different sources and if damage occurred simultaneously in different sites. From 91 events, only the event of 4 August 1868 was excluded. The flood database of the WSL (1972-2009) is considered to be complete.

\subsection{Instrumental and proxy data}

Solar forcing is considered an external driver of climate dynamics (Stuiver et al., 1997; Versteegh, 2005) and may influence flood frequency (Benito et al., 2003; Schulte et al., 2008, 2015). Average annual sunspot numbers (SN) for the period 1700-2011 were downloaded from the online catalogue of the sunspot index provided by the SIDC team (World Data Center for the Sunspot Index, Royal Observatory of Belgium, Monthly Report on the International Sunspot Number). To complete this analysis, we used a solar proxy, the annual mean values of the beryllium-10 records $\left({ }^{10} \mathrm{Be}\right)$ measured in the ice core from the NGRIP site in Greenland (Berggren et al., 2009). Deposition of atmospheric ${ }^{10} \mathrm{Be}$ into polar ice sheets is a natural archive with annual resolution about past solar activity and constitutes a proxy for understanding possible connections between solar variability and past climate change (Beer et al., 2000; Berggren et al., 2009).

Volcanic eruptions are investigated by mean volcanic sulphate deposition and converted to stratospheric volcanic sulphate injection (in $\mathrm{Tg}$ units) for the Northern Hemisphere over the past 200 years (1800-2000). These measures have been extracted from 32 ice core records that cover a major part of the Greenland ice sheet (Gao et al., 2008).

Climate variability is analysed from a climate proxy, the annual mean values of the oxygen isotope record $\delta^{18} \mathrm{O}$ for the period 1800-1987 from the Greenland ice core GISP 2 (Stuiver and Grootes, 2000). This core provides climate information based on conversion of isotope values to mean annual temperature in Greenland. Furthermore, we determined the average annual temperature for Switzerland from 1800 to 2006 based on data obtained from the EC project: multicentennial climate variability in the Alps (ALP-IMP, 2006). This data set is based on instrumental data, model simulations and proxy data, with the purpose of creating a spatial grid of several climate variables. The average temperature was obtained by calculating the arithmetic mean of the grid points corresponding to Swiss territory.

The low-frequency atmospheric variability modes were inferred from the daily EMSLP grid taken from the 20th Century V2 Reanalysis Project (20CRP). These data were provided by NOAA/OAR/ESRL PSD, Boulder, Colorado (Compo et al., 2011) and extend the temporal coverage of the NCEP/NCAR Reanalysis Project (Kalnay et al., 1996). The 20CRP is a mission to produce reanalyses of weather maps covering the period from 1871 onwards with a horizontal spatial resolution of $2^{\circ}$. To complete the period covered by the flood data (from 1800 to 2009) and to obtain a continuous time series of low-frequency atmospheric variability indices, the reconstructed monthly sea level pressure fields over the North Atlantic and Europe, generated by Luterbacher et al. (2002) for the years 1659-2000, were also integrated. 
A complete reference list of web links to the different data sets used in the analysis is given at the end of the manuscript.

\section{Methods}

Given the hydro-climatic differences according to the singular orographic configuration of Switzerland, the trigger processes of floods, especially rainfall generation processes, are different between the northern and southern flank of the Alps (Schmocker-Fackel and Naef, 2010). Although there are several Swiss climatologic and hydrologic regionalization studies (e.g. Kirchhofer, 2000), we conducted a regionalization of the Swiss territory based on a multivariate data analysis. The input data were performed by the matrix of INU (see Sect. 2.1.1). To identify the principal hydro-climatic regions, we applied principal component analysis (PCA) to the flood matrix in $\mathrm{S}$ mode using the correlation matrix. The critical assumptions underlying PCA are more conceptual than statistical. Only normality is necessary if a statistical test is applied to the significance of the factors. The data matrix should ensure that sufficient correlations exist to justify the application of factor analysis (Hair et al., 1998). Two tests were used to evaluate the model: the Kaiser-Meyer-Olkin measure of sampling adequacy (KMO) and Bartlett's sphericity test. The KMO statistic varies between 0 and 1 . A value close to 1 indicates that patterns of correlations are compact and therefore PCA should yield distinct and reliable factors. According to Kaiser (1974) the recommended acceptable values should be greater than 0.5 . If the KMO value is less than 0.5 we can evaluate the anti-image correlation matrix to delete redundant variables (that is to say, those variables that have values less than 0.5 in the principal diagonal) to improve the results of PCA. Bartlett's sphericity test checks the presence of correlations among the variables. It tests the null hypothesis that the correlation matrix is an identity matrix, i.e. all diagonal elements are 1 and all off-diagonal elements are 0 , implying that all of the variables are uncorrelated. If the significance value (sig. value) for this test is less than our alpha level $(\alpha)$, we reject the null hypothesis. Finally, we used the scree test to extract the most relevant components and the equamax normalized rotation for a straightforward interpretation of the model output. This rotation is a compromise between varimax and quartimax. Specifically, it maximizes the sum of variances of the squared raw factor loadings across factors and the same process across variables. This is equivalent to simultaneously maximizing the variances in the rows and columns of the matrix of the squared raw factor loadings.

INU is calculated separately for each of the regions determined from the PCA by evaluating the different spatial and temporal patterns that account for the variability in the frequency of floods. The INU is estimated taking a risk $(R)$ approach, whereby the concept of risk $(R)$ is considered to be the product of hazard $(P)$ and vulnerability $(V)$ :

$R=P \cdot V$.
The variable $P$ is estimated from the damage and economic losses caused by floods. The categories of damage are as defined in Sect. 2.1.1. To each category an arbitrary magnitude is attributed: floods classified as VS are given a value of 50 , while $\mathrm{C}$ floods are assigned a value of 100 . Thus, each flood event is defined by a $P$ value that indicates the intensity of the phenomenon. The estimation of $V$, defined as the spatial distribution of the phenomenon, is based on the number of cantons affected by a flood episode. Finally, by applying Eq. (1) we obtain an $R$ value for each flood event.

$R_{K}=\sum_{i=1}^{m} P_{i} * V_{i}$

$K$ is the flood number (ordinal 1 to $N$ where $N$ is the total number of floods), $m$ is the number of the cantons concerned in the flood number $K, P_{i}$ is the hazard of the flood number $k$ and the canton $i$ and $V_{i}$ is the vulnerability of the flood number $K$. In our case $V_{i}=1$ always. The INU is calculated from the integration of all the $R$ values on an annual resolution:

$\mathrm{INU}_{\text {year }}=\sum_{i=1}^{j} \sum_{K=1}^{n} R_{K}$.

$\mathrm{INU}_{\text {year }}$ is the INU value for a given year, $j$ is the number of the months (1 to 12) and $n$ is the number of events in a given month $j$. Finally, each $\mathrm{INU}_{\text {year }}$ is standardized, based on the mean and standard deviation; both parameters are calculated for the period 1800-2009.

The periodicities of the time series were determined by conducting analyses in the frequency domain. Spectral analysis is a useful tool for examining the information inherent in a time series (Schulz and Statteger, 1997; Schulz and Mudelsee, 2002; Borgmark, 2005). In this study, we used a harmonic analysis to detect periodic signals in the records with presence of noise (Percival and Walden, 1993). The time series were processed using the program SPECTRUM (Schulz and Statteger, 1997), which is based on a periodogram calculated from the Lomb-Scargle Fourier transform, with a rectangular window, and using a significance level of $0.05(\alpha=0.05)$ and a lambda of $0.4(\lambda=0.4)$. This configuration detects a false-alarm level of $99.6 \%$ for white noise assessment through the Siegel (Siegel, 1979) test. The red noise spectrum of the records is estimated with the REDFIT software (Schulz and Mudelsee, 2002). This program estimates the autoregressive first-order parameter for unevenly spaced time series and transforms this model into the time domain frequency. To assess, validate and explain the common cyclicities detected in the time series from the harmonic analysis, a cross-spectral analysis (Schulz and Statteger, 1997) was performed using the bivariate spectral analysis module of the program SPECTRUM. This program analyses the coherency and phase spectra to summarize the covariation of the time series particularly in palaeoclimatic records (Shackleton, 2000). 
A further methodology is concerned with the definition of low-frequency atmospheric variability modes. Several authors use the main EOF calculated from principal component analysis (PCA) in S mode applied to the grid of EMSLP using the covariance matrix (Hurrell et al., 2003; Folland et al., 2009; Bladé et al., 2011) and the scree test (Cattell, 1966) to extract the most relevant components without applying any kind of rotation. The analysis was conducted for the domain from 30 to $70^{\circ} \mathrm{N}$ and from $30^{\circ} \mathrm{W}$ to $30^{\circ} \mathrm{E}$ for the period 1800-2009. To cover the entire period, we used the reconstruction of sea level pressure fields, weighted by the square root of the latitude over the eastern North Atlantic and Europe, generated by Luterbacher et al. (2002) and the 20CRP (Compo et al., 2011).

\section{Results}

\subsection{Regionalization of Switzerland and INU as a flood damage index}

A total of 90 category VS and C floods were recorded in Switzerland in the period 1800-2009. The regionalization of Switzerland is based on the application of a PCA to the flood matrix. The KMO measure of sampling adequacy is 0.82 , which would be labelled as very good. Since this measure meets the minimum criteria to evaluate the correlation patterns of the data set, we do not have a problem that requires us to examine the anti-image correlation matrix to delete the redundant variables of the analysis. The result of Bartlett's sphericity test shows that sig. value $=0.000<\alpha=0.05$ (chisquare $=2128.42$, degrees of freedom $=325$ ). The sig. value for this analysis leads us to reject the null hypothesis and conclude that there is no evidence that the correlation matrix is an identity matrix and the data set is appropriate for the application of the PCA. The 2-D plot of the two principal components (not rotated; see Fig. 1a) accounts for $22 \%$ of the total variance. When the factors are inverted and rotated by $90^{\circ}$, they display the geographic location of the cantons approximately. This two principal components can be interpreted as the two principal moisture sources that affect Switzerland. Factor 1 is related to a disposition north/south of the cantons, indicating a lower/greater influence of the Mediterranean Sea. The second factor is explained by the west/east cross section, suggesting the higher/lower influence of the Atlantic moisture source.

We used the scree test to extract the most relevant components (see Fig. 1b) and we performed an equamax rotation in order to achieve the final regionalization of Switzerland considering the two cross sections. The analysis revealed five principal components accounting for $45 \%$ of the total variance. Each region is defined by a component (see Fig. 1c): the region 1 is composed of the Valais and the western cantons, region 2 is defined by the western part of the northern slope of the Alps and the western Swiss Plateau, region 3
A)

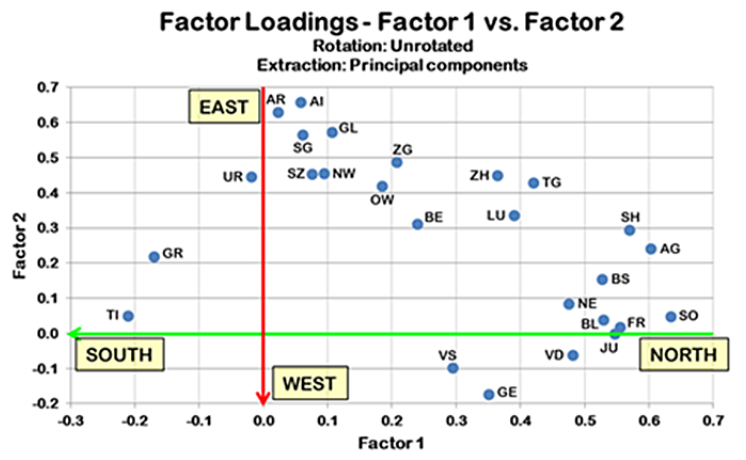

B)

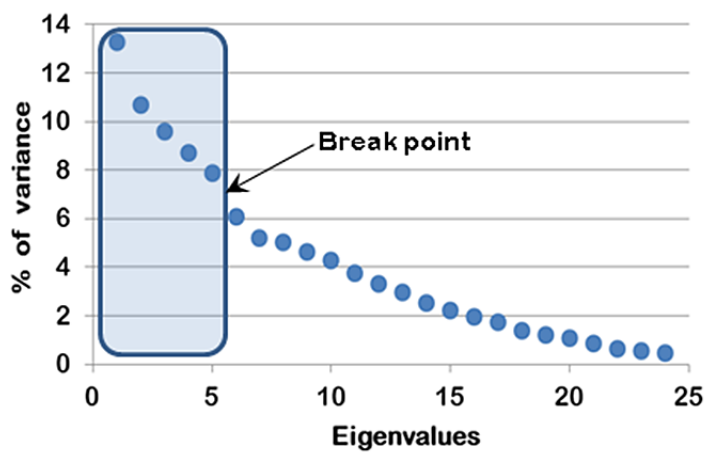

C)

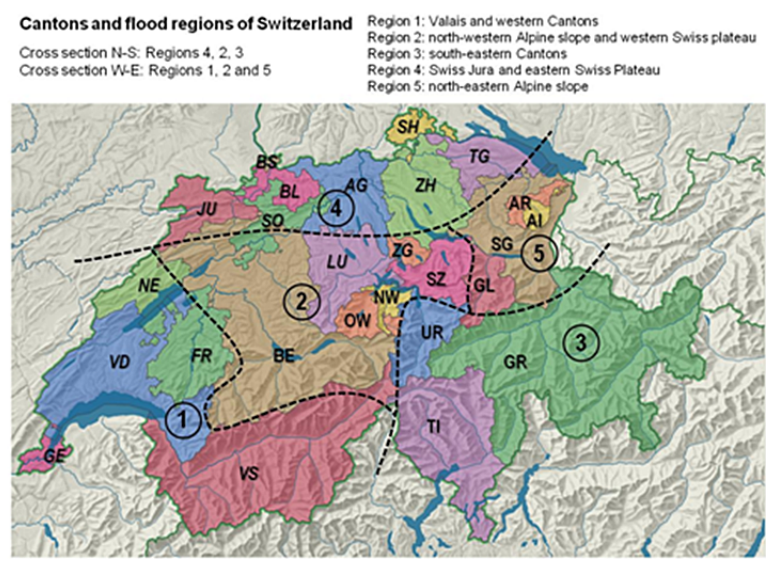

Figure 1. (a) Factor loadings of factor 1 versus factor 2 after the application of the PCA to the flood matrix without rotation. (b) Scree test and number of components selected. (c) Regionalization of Switzerland according to the PCA, applying the equamax rotation. The dotted lines show the limits of the regions (DEM from Atlas of Switzerland, 2004; map modified).

represents the south-eastern cantons Grisons, Uri and Ticino, region 4 is the Swiss Jura and the eastern Swiss Plateau and finally, region 5 is the eastern part of the northern flank of the Alps. Thus, the rotation improves the division of regions that appear vaguely defined in Fig. 1a. For instance, Uri (UR) marks the transition between regions 3 and 5 and finally is added to region 3. Moreover, the cantons located in northern and north-western Switzerland, which in Fig. 1a apparently define a single cluster, are split into two areas (region 1 and region 4) after the rotation. This separation probably distin- 


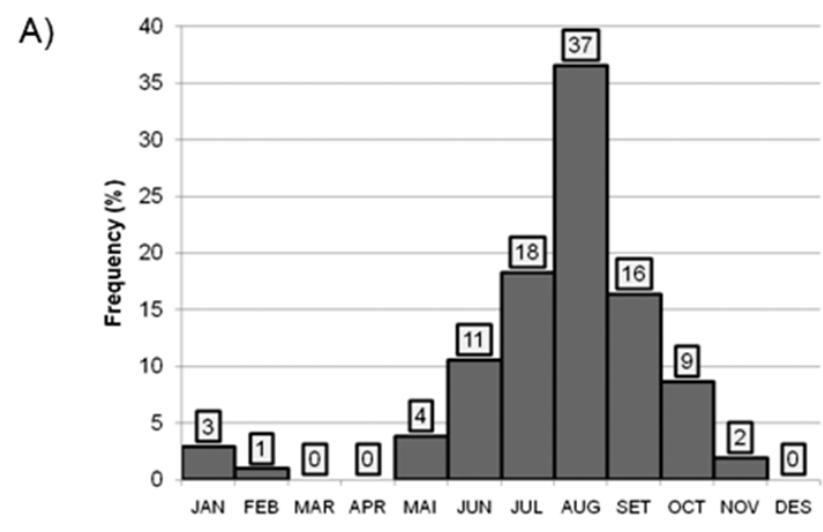

B)

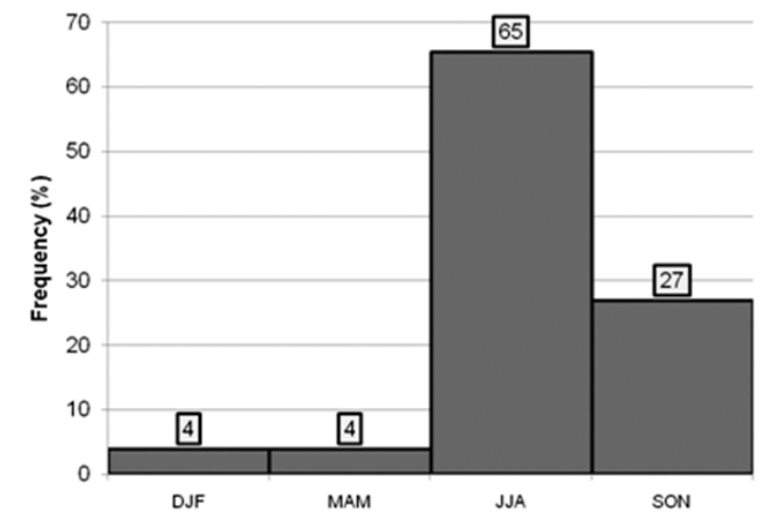

Figure 2. (a) Monthly distribution of major floods in Switzerland for the period 1800-2009 for very severe (VS) and catastrophic (c) flood categories. (b) Seasonal distribution of VS and C floods. DJF: December-January-February; MAM: March-April-May; JJA: June-July-August; SON: September-October-November.

guishes between the flows from the west-northwest and those from the north.

Figure 2 shows the monthly and seasonal distribution of VS and C events for the period 1800-2009. The monthly (Fig. 2a) and seasonal (Fig 2b) flood cycles are heavily pronounced: $65 \%$ of these events are concentrated in the summer season (June, July and August), rising to $82 \%$ if September is included (extended summer). Furthermore, the monthly distribution presents a peak in August with $37 \%$ of all events. It should also be noted that during the months of March, April and December, no major floods were recorded. Recall, however, that the flood damage index only considers the events recorded during the high summer months (July and August). We proceed in this way for two main reasons: first, this is the time window considered by the EOF1, which is the principal pattern for explaining rainfall patterns in terms of large-scale atmospheric phenomena; and, second, most of the catastrophic floods $(\mathrm{C} ; 60 \%)$ reported during the time span of this study occurred during this 2-month period.

Figure 3a shows the annual flood damage index according to the contribution of each region. The INU captures the high temporal variability of floods showing the alternation of high-frequency periods of major flood events and periods of very low frequency or flood gaps. The advantage afforded by the INU is that we are able to process the time series statistically. Figure $3 \mathrm{~b}$ shows the total annual INU values of the Switzerland and indicates periods with high frequency of flooding (grey shaded). Each column summarizes the information shown in Fig. 3a by using the following expression:

$\mathrm{INU}_{\text {year }}=\left(\sum_{i=1}^{N} \mathrm{INU}_{i},\right) \frac{1}{N}$,

where for a determined year, $i$ is the region number, $\mathrm{INU}_{i}$ is the $\mathrm{INU}_{\text {year }}$ for the region $i$ and $N=5$ (total number of regions). Finally, the new data set is normalized by the mean and the standard deviation of the period 1800-2009. The major flood periods can be identified with respect to INU values that exceed the mean plus 1.5 times the standard deviation. The first period marked by a high frequency of major floods (Fig. 3b) extends from 1817 to 1851 ; the second period from 1881 to 1927 , although some flooding did continue to occur, albeit less frequently, up to 1951 (Fig. 3a); the last two periods were recorded from 1977 to 1990 and 2005 to present. Since that date, the 2005 flood event has caused the most severe damage (CHF 3.1 billion) followed by the 1987 flood (CHF 1.77 billion).

\subsection{Spectral analysis of large floods}

Figure 4a plots the harmonic analysis of the INU undertaken to detect periodicities in the records in the presence of noise (Schulz and Statteger, 1997; Schulz and Mudelsee, 2002; Borgmark, 2005). The analysis identifies periodic signals that are above the $99.6 \%$ false-alarm level using the Siegel test, in an interval of frequencies (fs) ranging between 0.005 and 0.011 with a maximum peak at 0.009 , at 0.082 , between 0.103 and 0.105 with a maximum peak at 0.105 and between 0.391 and 0.413 with a maximum peak at 0.393 . A red noise in the signal (Fig. 4b) was not detected. Thus, the harmonic analysis indicates spectral peaks between 92 and 184 years with a maximum spectral peak at 110 years, between 10 and 12 years with a maximum spectral peak at 10 years and between 2 and 3 years with a maximum spectral peak located at 2 years. In summary, significant spectral peaks were detected around 2, 10 and 110 years. These latter two may correspond, respectively, to the Schwabe ( $11.0 \pm 2.02$ years) and Gleissberg cycles $(88.6 \pm 21$ years); such secular periodic processes have been reported in a broad variety of solar, solar-terrestrial, and terrestrial climatic phenomena (Peristykh and Damon, 2003), whereas the first one might correspond to the quasi-biennial oscillation (Baldwin et al., 2001), that it affects the stratospheric flow from pole to pole by modulating the effects of extratropical waves. The spectral analysis therefore seems to provide evidence that solar forcing is a significant factor with regard to the timing of floods in Switzerland. 
A)

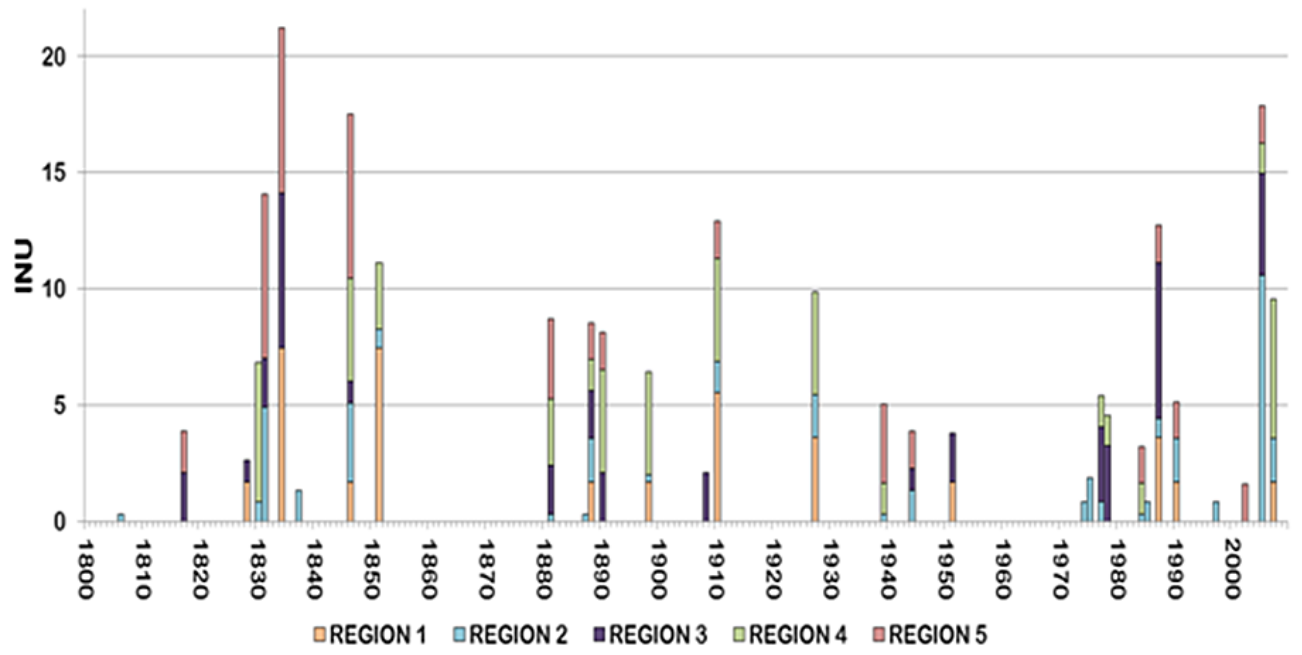

B)

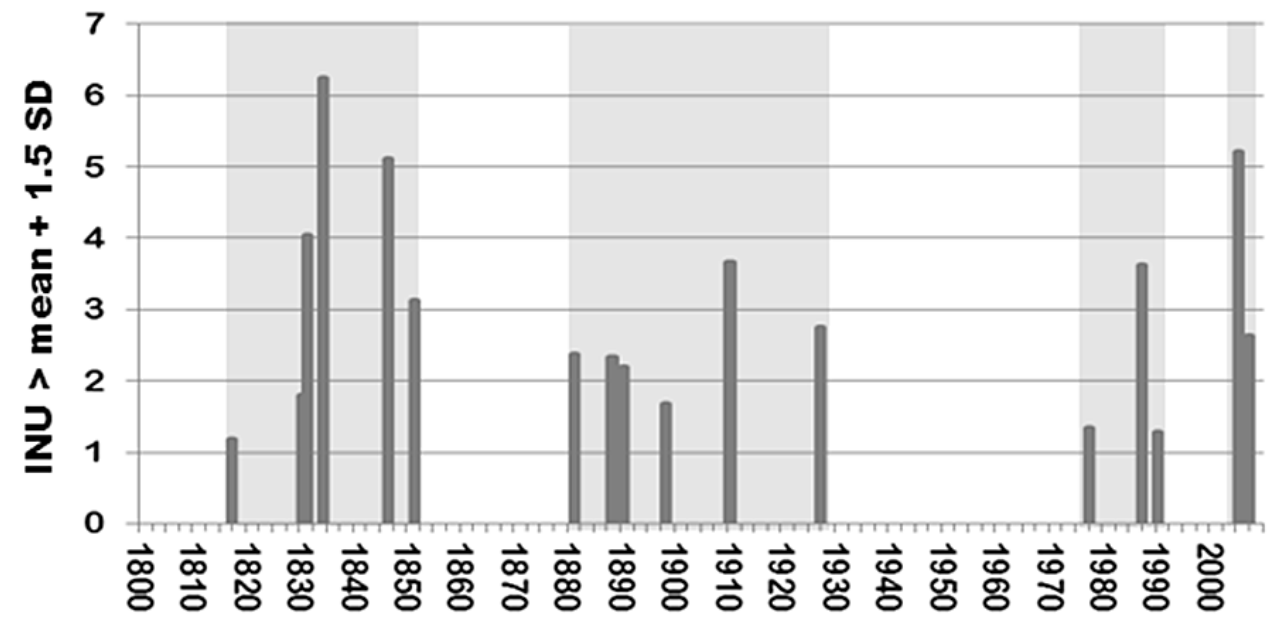

Figure 3. (a) Regional flood damage index INU for the period 1800-2009. (b) Values of INU that exceed 1.5 times the standard deviation. The periods with a high frequency of flooding are shaded grey.

\subsection{Cross-spectral analysis between sunspot numbers and large floods}

To compare the periodicities identified in the INU with cycles of solar activity, a harmonic analysis of the annual average sunspot number for the period 1700-2011 was conducted. The results show the main solar cycles on decadal and centennial scales (Fig. 4c) and are consistent with the results of solar periodicities reported by Rogers et al. (2006). The INU shows common periodicities with solar cycles at 0.010 and 0.090 , corresponding to 104 and 11 years, respectively.

To consider the significance of the common spectral peaks of INU and the sunspot record, a cross-spectral analysis was undertaken to obtain the coherency and phase spectra (Fig. 5). Since maximum values in the INU are expected to correlate with minimum solar activity values, as pointed out in a number of studies (e.g. Pfister, 1999; Magny et al.,
2003; Schulte et al., 2009a, b), the sign of the INU data was changed prior to cross-spectral analysis to prevent an artificial phase offset by $\pm 180^{\circ}$. The coherency spectrum (Fig. 5a) suggests the presence of periodic components at 104, 22 and 11 years, setting the false-alarm level at $\alpha=0.1$. The phase spectrum (Fig. $5 \mathrm{~b}$ ) identifies negative angles of $-117^{\circ} \pm 20^{\circ}$ at 0.010 (104 years), and $-98^{\circ} \pm 48^{\circ}$ at 0.090 (11 years). These results show that the maximum INU values are related to solar activity minima. However, the angle is positive $\left(132^{\circ} \pm 19^{\circ}\right)$ at $\mathrm{fs}=0.045$ (22 years). Therefore, the cross-spectral analysis provides evidence that the common and significant periodicities detected in the coherency spectrum at 11 (Schwabe cycle) and 104 years (Gleissberg cycle) are related to a high frequency of flooding and minimum solar activity (negative angles in the phase spectrum, Fig. 5b), whereas the 22-year cyclicity detected (Hale cycle) is associ- 
A)

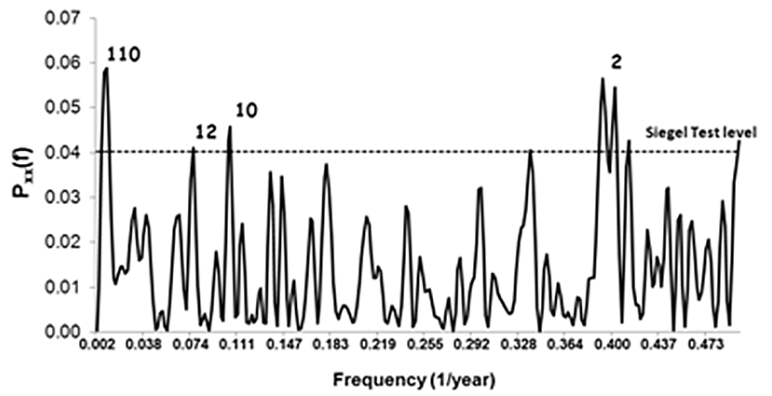

B)

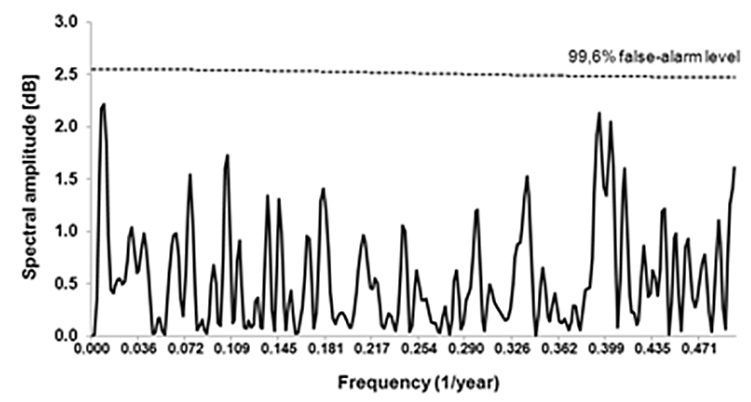

C)

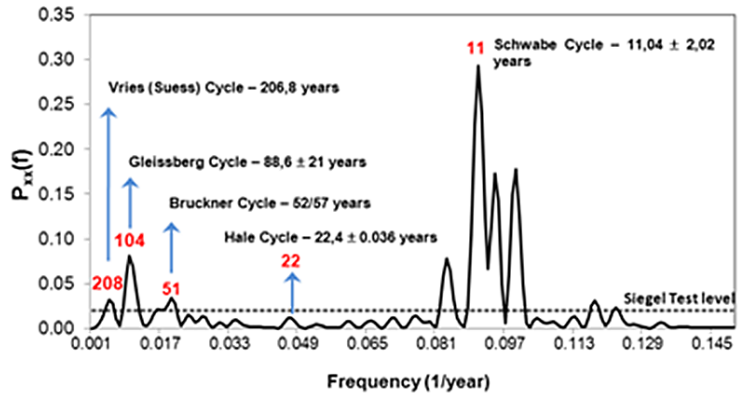

Figure 4. (a) Harmonic analysis for the summer flood damage index INU. The dotted line represents critical level for the Siegel test and significant frequencies are shown in years. (b) Red noise AR1 spectra of INU. The dotted line shows false-alarm level. (c) Harmonic analysis for the average annual number of sunspots. The dotted horizontal lines represent critical levels for the Siegel test. Significant frequencies are shown in years. The principal solar cycles are highlighted.

ated with maximum solar activity and a decrease in the flood frequency (positive angles in the phase-spectrum).

\subsection{Comparison between modes of low-frequency atmospheric variability and large floods}

The INU index provides an excellent tool to explore the space-time dependence between major floods in Switzerland and low-frequency atmospheric variability patterns. During the high summer, the climate variability in the North Atlantic-European sector is synthesized by a major annual variability pattern identified as the EOF1. This pattern was detected by the first covariance eigenvector of EMSLP com-
A)

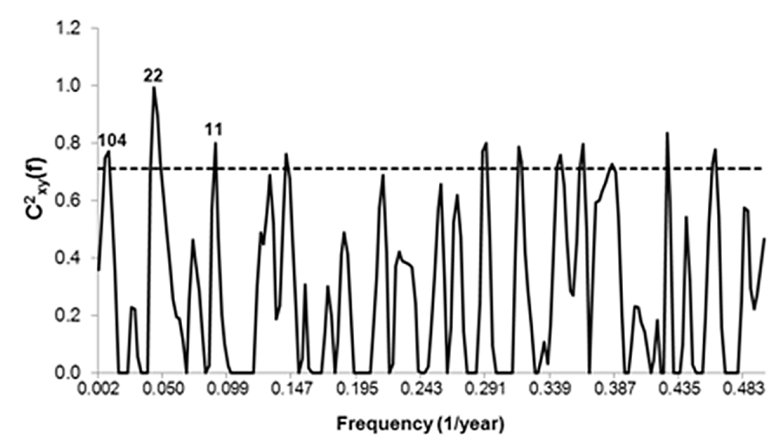

B)

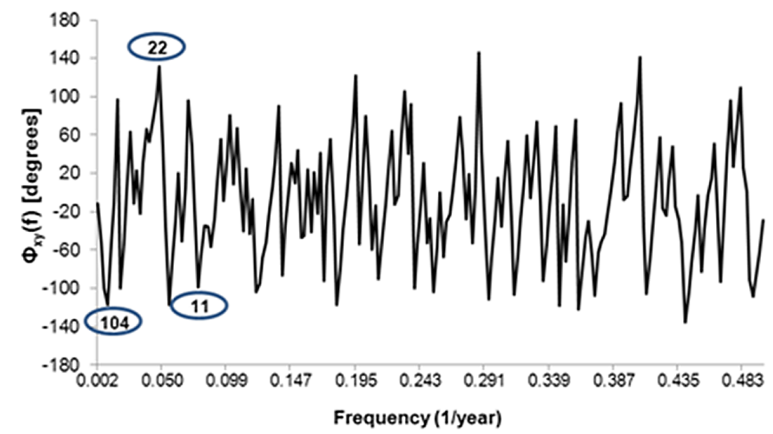

Figure 5. Cross-spectral analysis between the index of summer flood damage INU and annual number of sunspots: (a) Coherency spectrum. Dashed line indicates false-alarm level for $\alpha=0.1$. (b) Phase spectrum. The sign of the INU data was changed prior to cross-spectral analysis in order to prevent an artificial phase offset by $\pm 180^{\circ}$. Negative angles indicate that the maximum frequency in the floods occurs during a solar activity minimum and vice versa.

puted from a PCA in S mode, over the domain $30-70^{\circ} \mathrm{N}$ and $30^{\circ} \mathrm{W}-30^{\circ} \mathrm{E}$, with a monthly resolution for the two reanalysis grids used: 20CRP (Compo et al., 2011) for the period 1871-2009 (Fig. 6a), and the sea level pressure fields over the North Atlantic and Europe for the period 1659 to 1999 (Luterbacher et al., 2002; Fig. 6b). The low-frequency atmospheric variability pattern obtained separately from both grids is quite similar, explaining roughly $40 \%$ of the EMSLP variance. Both models are comparable to those presented by Folland et al. (2009, see Fig. 1, pp. 1085). Furthermore, the coefficients of the scores matrix report the temporal evolution of the EOF1. The Pearson temporal correlation coefficient between the scores of both time series has a value of 0.89 . This level of association has allowed us to create the EOF1 index for the period from 1800 to 2009 (see Fig. 6c).

The temporal evolution of EOF1 (Fig. 6c) shows three periods dominated by positive phases: the first between 1741 and 1783, the second, more intermittently, between 1867 and 1918, and the third since 1967. The temporal evolution is very similar to that presented by Folland et al. (2009, see Fig. 3, p. 1087). The second and third phases coincide with the last three phases of high-frequency flooding in Switzer- 


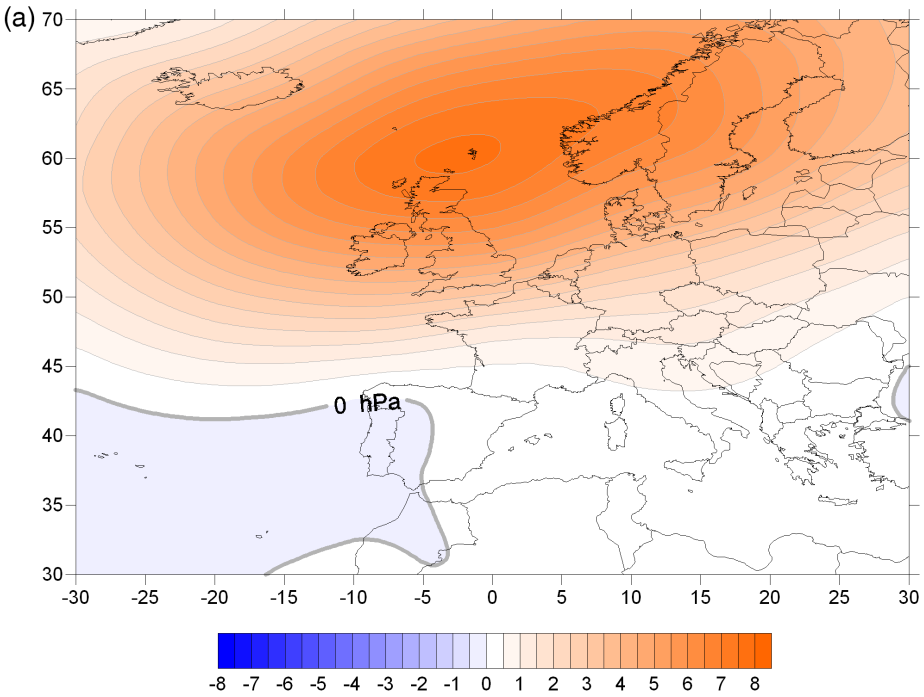

(b) 70

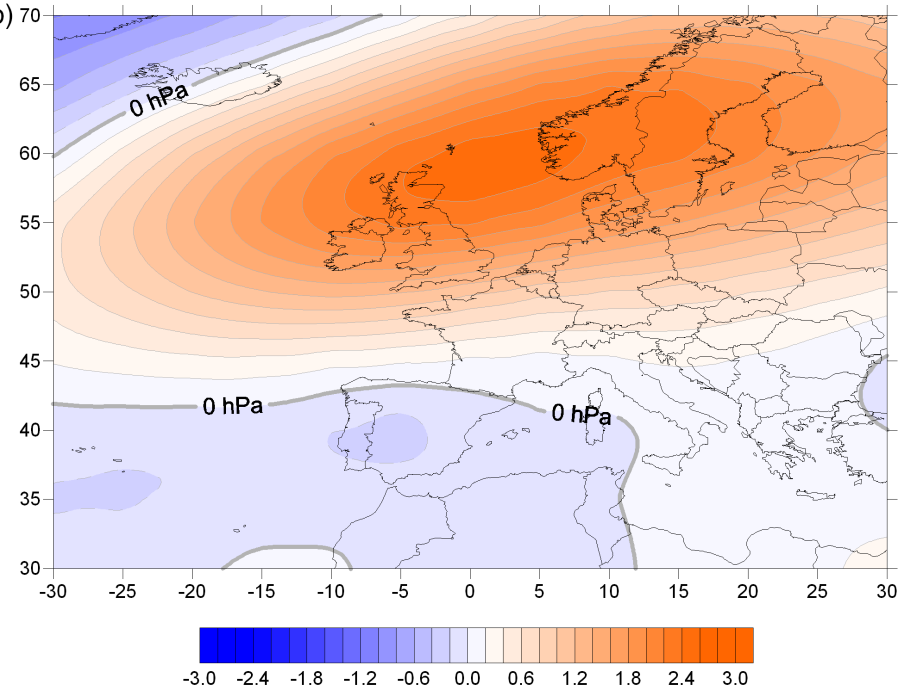

(c)

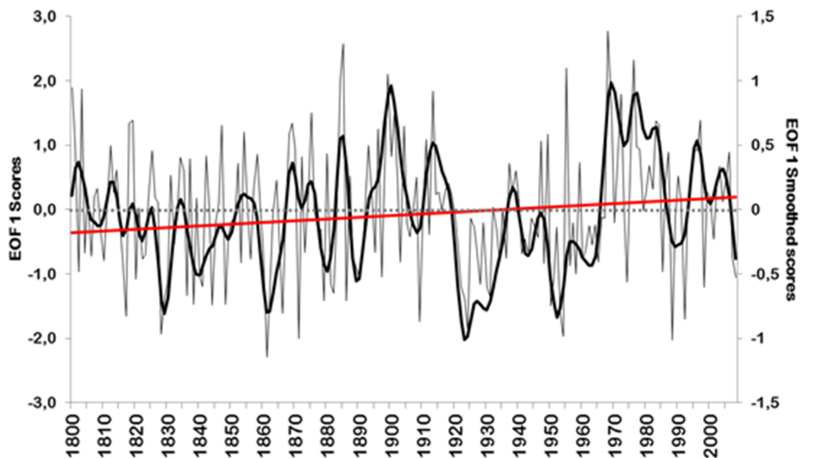

Figure 6. (a) Principal mode of low-frequency atmospheric variability based on principal eigenvector extracted from PCA in S mode, using the covariance matrix of monthly EMSLP for the period 1871-2009 (EOF1). This has been applied to the grid extracted of the 20th Century Reanalysis project (Compo et al., 2011). The red (blue) contours show positive (negative) anomalies. (b) As in (a) but applied to the monthly EMSLP of the Luterbacher reanalysis grid (Luterbacher et al., 2002) for the period 1800-1999. (c) Time series of the EOF1 pattern for the period 1800-2009 (thin black line) smoothed by a low-pass Gaussian filter of 11 years (black line). The red line shows the trend of the EOF1 time series (significant and positive trend at a $95 \%$ confidence level, $p$ value $=0.006$ ). 
land. In addition, the positive phase of EOF1 detected in the 18th century coincides with the flood cluster between 1740 and 1790 reconstructed by Schmocker-Fackel and Naef (2010b). Only the high-frequency phase of major floods that was recorded during the first half of the 19th century (cf. Fig. 3b) is not reflected in the temporal evolution of the EOF1 data.

The increase in flood frequency occurs mostly in the positive phases in the large-scale variability pattern for the high summer period. Flood events with INU > 5 SD (Fig. 7a) correlate with positive EOF1 values (Pearson's temporal correlation coefficient is 0.45 , significant at the $95 \%$ confidence level). However, the study of the complete amplitude of the INU and EOF1 signals (Fig. 7b) indicates a second flood pattern during negative phases of EOF1. Table 1 shows the mean values of EOF1 for the years assigned to four categories of the INU whose thresholds were defined according to the standard deviation (from INU >0 SD for at least one major flood to INU $>5 \mathrm{SD}$ for highest flood impacts). The 33 summers with very severe or catastrophic floods in Switzerland (INU >0 SD) show a weak positive value of EOF1 $=0.04$ ( \pm 0.90$)$, which increases to $0.45( \pm 0.90)$ when considering only those summers that have recorded a flood with a large impact (INU > 5 SD). The number of years involved in INU $>0$ with positive phase of EOF1 is also higher than the years associated with a negative phase (20 and 13 , respectively), noting that the 4 years involved in the major floods all have a positive value of EOF1. However, with regard to a reliable explanation of the triggering processes for floods in Switzerland which are based on large-scale atmospheric patterns, we also observe a significant number of years in the negative EOF1 phase. In addition, this is shown by the second percentile (see Table 1) indicating negative values of EOF1 up to INU > 2.5 SD. In Sects. 5.1 and 5.4 we focus on the issue of whether the observed differences in the behaviour of the positive and negative EOF1 phases are linked to the two spatial patterns associated with the hydro-climatic regionalization (see Sect. 5.1 and Fig. 8). Moreover, we briefly analyse whether there have been changes in low-frequency atmospheric variability patterns associated with major floods during the last 200 years.

\section{Discussion}

\subsection{Hydro-climatic regionalization and flood periods in Switzerland}

The hydro-climatic regionalization performed by the PCA shows two patterns of spatial variability related to the two principal moisture sources that affect Switzerland: Mediterranean and Atlantic humidity supplies. The first pattern is related to the north-south cross section while the second pattern is defined by the west-east cross section (see Fig. 1a). Taking into account these findings, the final classification
A)

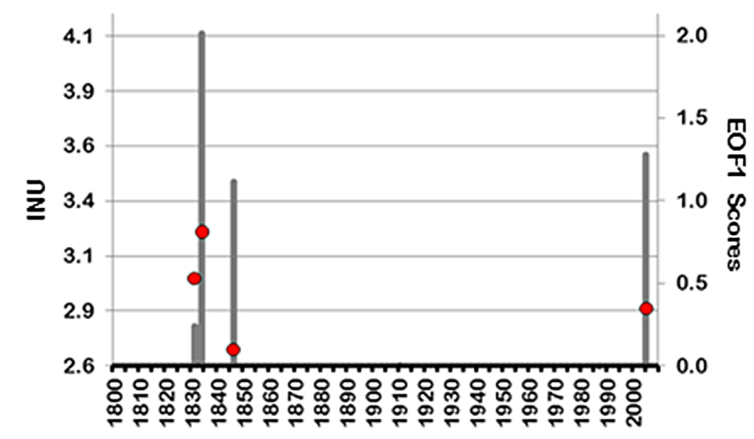

B)

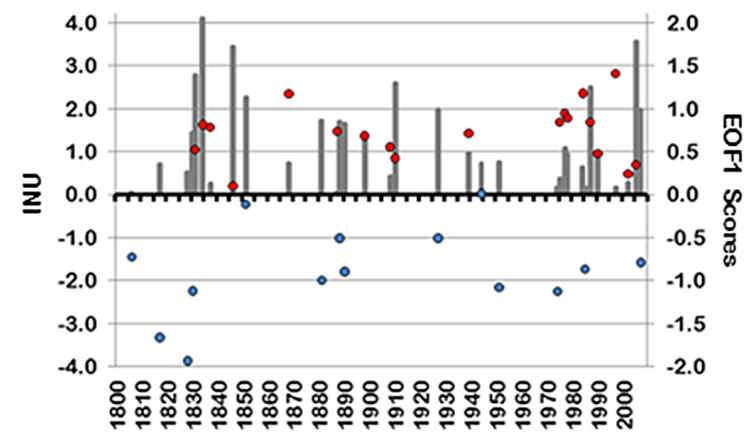

Figure 7. (a) Summer flood damage index INU (bars) versus positive phase of EOF1 (red dots) for values of INU 5 times greater than the standard deviation (INU > 5 SD). (b) As in (a) but for the complete signal of the INU. Blue dots represents negative EOF phase.

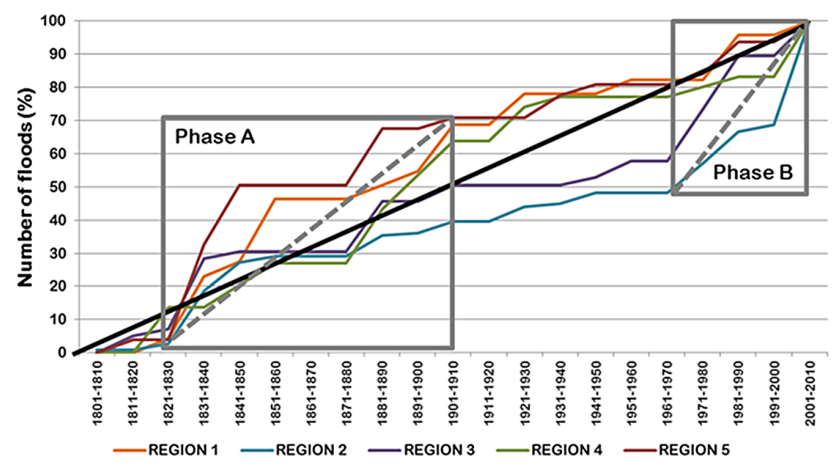

Figure 8. Cumulative number of floods (in \%) versus time, for each region: the cumulative frequencies are obtained by adding the absolute frequencies of all years up to the year referred to. Black line: Bisector of the quadrant where the distribution of the floods is perfect.

presents five different regions (see Fig. $1 b$ and c). The two cross sections stress the regionalization based on the INU index. The three physiographic units, the Jura, Swiss Plateau and Alps are related to different sources of humidity. The northern slope of the Alps and the Swiss Plateau are divided into three regions linked to the proximity to the Atlantic fluxes. In addition, the region 2 (particularly the Bernese Alps) marks the intersection of both patterns: on one hand 
Table 1. Principal statistical parameters of EOF1 for each of the categories of the flood damage index INU whose thresholds were defined according to the standard deviation (SD).

\begin{tabular}{lrrrr}
\hline & $\mathrm{INU}_{i}>0 \mathrm{SD}$ & $\mathrm{INU}_{i}>1.0 \mathrm{SD}$ & $\mathrm{INU}_{i}>2.5 \mathrm{SD}$ & $\mathrm{INU}_{i}>5.0 \mathrm{SD}$ \\
\cline { 2 - 5 } Average & 0.04 & 0.10 & 0.18 & 0.45 \\
\hline EOF1 + (years) & 20 & 11 & 6 & 4 \\
EOF1 - (years) & 13 & 7 & 3 & 0 \\
$N$ & 33 & 18 & 9 & 4 \\
Max & 1.41 & 0.94 & 0.84 & 0.81 \\
Min & -1.93 & -1.12 & -0.79 & 0.10 \\
P95 & 1.18 & 0.90 & 0.83 & 0.77 \\
P2 & -1.76 & -1.08 & -0.74 & 0.12 \\
\hline
\end{tabular}

the Atlantic flux and on the other hand the moist Mediterranean air masses that flow across the Alps and encounter the cooler Atlantic air at the northern Alpine slope (Pfister, 1999).

The regional distribution is consistent with other classifications of Switzerland (e.g. Kirchhofer, 2000) that have been widely used such as for weather forecast and warnings for heavy rain (Schmocker-Fackel, 2010a). A major drawback of our classification is that regions have been constructed from administrative units (cantons) that in some cases may include different physiographic units. For example region 2 includes the canton Berne which range from the northern Alps to the Swiss Plateau and the southern slopes of the Jura Massif. However, the classification avoids the overestimation of the small Swiss cantons.

The temporal evolution of the regional INU shown in Fig. 8 indicates two spatial flood patterns: during phase A from 1820 to 1910 flood numbers increased in the basins of the west and northern flank of the Alps (region 1, 4 and 5), whereas during phase B from 1970 to the present floods increased in the centre and south of the Alps (regions 2 and 3). This decadal variability might be linked to changes in patterns of extreme precipitation and large-scale atmospheric variability (Frei et al., 2000). Schmocker-Fackel and Naef (2010a) suggest that this changing atmospheric pattern is not well defined for Switzerland yet.

The total INU index, summarizing the temporal distribution of the frequency of very severe and catastrophic floods in Switzerland, presents four major flood periods: the first extends from 1817 to 1851 , the second from 1881 to 1927 , the third encompasses 1977 to 1990 and the fourth was initiated in 2005 (Figs. 3b and 9). These periods largely coincide with those reported in other studies for Switzerland (HächlerTanner, 1991; Röthlisberger, 1991; Gees, 1997; Pfister, 1999; Schmocker-Fackel and Naef, 2010b) and, furthermore, with the periods identified in Spain, Italy and the Czech Republic (Barriendos and Rodrigo, 2006; Camuffo and Enzi, 1996; Brázdil et al., 2006). Our study shows that periods of high-frequency flooding have a period around 90 years. This range is very similar to that observed in Germany: for in- stance, Glaser and Stangl (2004) report flood clusters that range between 30 and 100 years during the last millennium, whereas in northern Switzerland these periods have a duration of between 30 and 120 years (Schmocker-Fackel and Naef, 2010b). In our opinion, the INU provides a robust index, which captures the variability in major flood frequency, although the distribution of the clusters is not homogeneous in time.

Pfister (1999) who reconstructed the floods of the Rhine, Rhone and Reuss rivers and of Lake Maggiore from documentary sources and instrumental data for the past 500 years found that major flood clusters occurred during cold periods of the Little Ice Age. The last flood pulse from 1827 to 1875 corresponds to the first period identified in our study (1817-1851). However, the Little Ice Age also included periods with no flood activity in alpine basins and which coincided with periods of decreased solar activity, such as the Maunder Minimum (Pfister, 1999). As for the flood analysis undertaken by Schmocker-Fackel and Naef (2010b) in Swiss catchments, the alternation of periods of high and low flood frequencies coincides with those reported in our study.

The single high flood frequency period between 1820 and 1940 identified by Schmocker-Fackel and Naef (2010b) appears in our INU index as two flood pulses separated by a short flood gap (1851-1881; Fig. 3b). The results compiled by Pfister (1999) from the Rhone, Reuss/Linth and Alpenrhein basins show a high flood frequency from 1860 to 1875 . This discrepancy can be explained in part by the different statistical processing methods applied to the flood data categories and by differences in the number of catchments studied (number of samples). In addition, the INU index only considers the very severe and catastrophic floods that occurred during the high summer months (July and August), whereas Pfister (1999) includes the total number of events in all seasons. However, all authors (Röthlisberger, 1991; Gees, 1997; Pfister, 1999) rule out any possible data incompleteness with regard to very severe and catastrophic floods on the grounds that the local press and administration paid considerable attention to extreme hydrological events following the application of the Swiss federal law, providing river cor- 
rection subsidies in 1848 . However, there is a consensus in the literature that the older the event (and, hence, the associated damage) is, the less clear the definition of the thresholds between the loss categories is.

A second flood gap is recorded from 1944 to 1972 by the INU reflecting the absence of extreme weather conditions (predominance of negative EOF1; Fig. 6c) that might trigger major floods. Pfister (1999) argues that anthropogenic influence (land use, deforestation) in the major floods is not the dominant driving factor, but rather the long-term summer precipitation minima between 1935 and 1975. According to Gees (1997), river regulation and the building of embankments and reservoirs substantially reduced the damage caused by smaller and medium floods after 1854, whereas the mitigation of the impact of very severe and catastrophic floods showed only limited success, particularly in the upper alpine catchments. Nevertheless, the more intensive land use in former flood areas protected by river embankments contributed to increased losses (Gees, 1997). Moreover, it is important to bear in mind that the general increase in population, exposure values (due to the increase in the gross domestic product) and urban agglomeration (e.g. Zurich) have contributed to higher flood damage indices, particularly in recent decades. A decrease in the number of floods is also reported by Schmocker-Fackel and Naef (2010b) for northern Switzerland between 1940 and 1970, and Wetter et al. (2011) observe a period of very low-frequency flooding in the city of Basel (Rhine river) for the period 1877-1999 and in Lindau (Lake Constance) for the 1910-1999 time interval.

Finally, the increase in flood events since 1977 recorded by the INU seems to have resulted from both increasing vulnerability and from changes in climate signal. With regard to this first factor, Glaser et al. (2010) found that even though the number of extreme hydrological events decreased compared to the 19th century, estimations of overall losses are substantially higher. This is related to the increased vulnerability and exposure values in flood prone areas as a consequence of the expansion of urban areas. As for the influence of climate variability on flooding in recent decades, Knox (2000) stated that the unusually high frequency of large floods which has been observed in many regions since the early 1950s occurred during a period of global temperature increase, and that the occurrence of extreme floods during the Holocene is often associated with rapid climate changes. In Switzerland, the flood frequency in many basins has increased since the 1970s (Gees, 1997; Pfister, 1999). However, SchmockerFackel and Naef (2010a) consider that the flood frequencies observed during the past 4 decades do not exceed the range recorded during the last five centuries.

\subsection{Possible control of solar variability}

In recent decades, the sun-climate relation has been analysed (Solanki and Fligge, 2000; Versteegh, 2005; Gray et al., 2005), with solar variability being proposed as a possible driving force of flood events (Benito et al., 2003; Vaquero, 2004). Schulte et al. $(2008,2015)$ consider the impact of solar activity on the regional hydrological regime (e.g. Gleissberg cycle) to have been one of the main factors triggering the major floods in the Lütschine and Lombach catchments in Switzerland over the last 3200 years.

By undertaking spectral analyses of the INU and the sedimentary proxies of the northern slopes of the Alps (Schulte et al., 2015), we are able to identify common flood cycles with a variation ranging between 70 and 150 years. The periodicities of so-called "100-year events" (according to Glaser et al., 2010) could be explained by centennial-scale solar cycles, which have also been identified in other sedimentary records, including those in eastern France, Switzerland, Netherlands, the UK, Spain and California (see, for example, Magny et al., 2003; Versteegh, 2005). Cross-spectral analysis between the INU and sunspot numbers suggests that the common and significant periodicities detected in the coherency spectrum of 11 (Schwabe cycle) and 100 years (Gleissberg cycle) coincide with the relation between a high flooding frequency and minimum solar activity (negative angles in the phase spectrum). This fact is supported by the findings of Wirth et al. (2013a) in the reconstruction of the summer floods in the southern European Alps. Furthermore, the 22-year cyclicity detected (Hale cycle) includes the link between solar activity maxima and decreased flood frequency (positive angles in the phase spectrum). This bi-decadal frequency of the INU "flood minima" is confirmed by climate proxies in the western United States where droughts occurred with a 22-year periodicity from 1700 onwards (Cook and Stockton, 1997; Briffa, 2000).

\subsection{Short-term external forcing on flooding}

To evaluate possible links between flooding and short-term external forcing fluctuations, the volcanic eruptions, EOF1, $\delta^{18} \mathrm{O},{ }^{10} \mathrm{Be}$ and sunspot number have been plotted alongside the INU index for Switzerland (Fig. 9). All the proxy series are plotted as normalized values smoothed with an 11-year low-pass Gaussian filter, except the sunspot number record smoothed with a 22-year filter, while volcanic eruptions and INU time series are not filtered. It should be noted that the links with solar and climate proxies can generate two types of problem: first, the time lags between sunspot numbers ( $\mathrm{SN}$ ), production and the deposition of ${ }^{10} \mathrm{Be}\left(1-2\right.$ years) and $\delta^{18} \mathrm{O}$ (from years to decades; e.g. the reconstructed time lags between ${ }^{14} \mathrm{C}$ and $\delta^{18} \mathrm{O}$ records during the Wolf and Maunder Minimum rise up to 40 years; Stuiver et al., 1997; Vonmoos et al., 2006; Abreu et al., 2012) in the natural archives have to be considered; and, second, the significance of the signal of the palaeoclimate proxies on the regional and global scale has to be interpreted. Despite these uncertainties, comparison of ${ }^{10} \mathrm{Be}$ concentration, sunspot numbers and temperature records from Greenland ice shows fairly good correlation from the 17th century onwards (Stuiver et al., 1995; Beer 
et al., 2000). However, other proxies such as the $\delta^{18} \mathrm{O}$ are influenced by the oceanic thermohaline circulation besides solar activity. However, it must be taken into account that the length of INU time series is relative short, covering 200 years, and linkages are based on only four flood periods and three flood gaps. Therefore, the relation between INU and the different climate proxies must be interpreted with caution and simple associations must not explain causal mechanism. Furthermore, it should be stressed that the INU signal includes uncertainties due to the integration of natural and anthropogenic variables. These reasons have to be borne in mind before discussing the following results.

Three periods of low solar activity (low number of sunspots, positive anomalies of ${ }^{10} \mathrm{Be}$ ) have been recorded during the last 200 years (Fig. 9; cf. Solanki and Fligge, 2000; Berggren et al., 2009): the first period covers the years leading up to 1840 , and corresponds to the final stages of the Dalton Minimum; the second period lasts from 1880 to $1910\left({ }^{10} \mathrm{Be}\right)$ and $1935(\mathrm{SN})$, corresponding to the solar minimum of 1900; and a third period begins after 2005, reaching minimum values in 2009. Figure 9 provides evidence that the periods marked by a high flood frequency typically correspond to periods characterized by a predominance of positive ${ }^{10} \mathrm{Be}$ anomalies and, therefore, associated with episodes of low solar activity. This pattern was particularly strong during the solar minimum of 1900. The period of high flood frequency between 1817 and 1855 largely corresponds to a period characterized by positive ${ }^{10} \mathrm{Be}$ anomalies, although the flood peaks occurred in the transition between a solar minimum and a solar maximum. During this period an extra cooling occurred which was associated with the eruption of Tambora (1814) plus two eruptions in the years 1831 and 1835 (Fig. 9). Considering both forcings (solar and volcanic), the temperature anomaly for this period compared to the $1961-1990$ mean was around $-0.5^{\circ} \mathrm{C}$ in the Northern Hemisphere (Gao et al., 2008) and $-1.1^{\circ} \mathrm{C}$ for the Swiss Alps (Büntgen et al., 2006). Finally, the maximum of the last flood cluster corresponds to a short period of low solar activity after 2005 .

Several authors (Pfister, 1999; Knox, 2000; Magny et al., 2003; Benito et al., 2003; Schulte et al., 2012; Ortega and Garzón, 2009) contend that the most significant variations in the frequency of flooding have occurred during cold climate phases, particularly during transitional stages of climatic pulses. This pattern has also been observed in Switzerland during the last 500 years (Schmocker-Fackel and Naef, 2010b; Glur et al., 2013; Wirth et al., 2013a, b), although after the 1970s the climate and flood pattern changed. The $\delta^{18} \mathrm{O}$ record GISP2 from Greenland (Stuiver and Grootes, 2000), influenced by North Atlantic dynamics, provides a proxy of the temperature variability in the middle and high latitudes of the Northern Hemisphere. The peak clusters of the flood damage index INU (Fig. 9) can be related to periods dominated by negative $\delta^{18} \mathrm{O}$ anomalies (bearing in mind that the axis is inverted), principally to the cooler pulses from 1830 to 1845 , from 1880 to 1930 and during the 1980 s.

To corroborate these results obtained from large-scale proxies, in Fig. 10 we plotted the normalized annual average temperature of Switzerland for the period 1800-2009 vs. the INU. The first two flood clusters occurred during a period of negative temperature anomalies between 1825 and 1935. In addition, these two flood clusters are related to pulses of marked temperature decreases separated by a flood gap which corresponds to a period of temperature recovery (slightly negative temperature anomalies $>-0.2{ }^{\circ} \mathrm{C}$ ) and solar activity (Fig. 9). The flood peak of summer 1987 occurs in a period in which temperature anomalies in Switzerland were slightly positive, but $\delta^{18} \mathrm{O}$ was negative in Greenland, indicative as such of the influence of North Atlantic dynamics. The 2005 and 2007 floods occurred in a clearly warm phase in Switzerland, corresponding to a contemporary maximum. However, the climatic interpretation of these events should be undertaken with caution because the final temperature data once again present a slight fall and sunspot numbers clearly decrease. Yet, these data represent the end of the time series. As for the pattern of flood gaps, Fig. 10 provides clear evidence: gaps of floods (1852-1880; 1928-1976) are related to positive temperature trends. Moreover, the contemporary flood cluster is divided by the positive trend towards the temperature maximum.

From the analyses of the various proxies, we infer that periods of decreased solar activity and low-frequency cold climate pulses $\left(\delta^{18} \mathrm{O}\right)$ have a significant impact on major summer floods in Switzerland. Nevertheless, the non-linear pattern of flood occurrences (e.g. since 1977) needs to be related to the complex relationship between exogenic, endogenic and autogenic climate forcing mechanisms. Therefore, hemispheric or global changes that occur in the atmospheric general variability or in ocean currents, and that affect storm tracks and air mass limits (Hirschboeck, 1988; Knox, 2000), should be considered when investigating periods of high flood frequency.

\subsection{Principal low-frequency atmospheric mode and flood variability}

The reanalysis of weather maps is a scientific method for obtaining an atmospheric data set to evaluate the spatial variability of climate over time. Several methods merge observations and numerical models to study the atmospheric conditions. Depending on the nature of original data, the temporal resolution can be seasonal, monthly, daily or 6-hourly. Normally, these reanalyses encompass several decades or centuries, covering different atmospheric levels. Reanalysis products are also used in climate research for identifying the causes of climate variability. However, atmospheric field reconstructions up to several centuries back in time may include caveats that should be considered when low-frequency atmospheric summer modes are interpreted to understand 


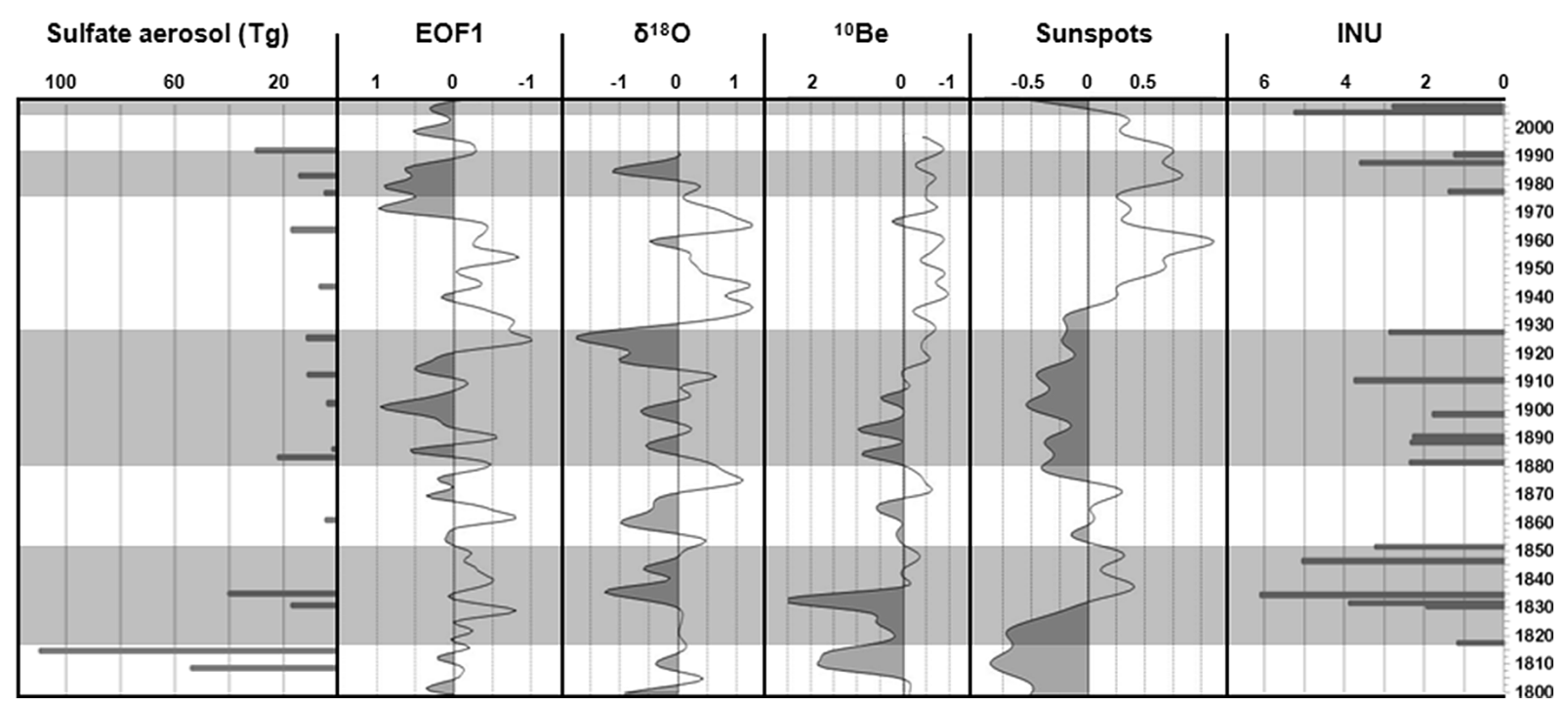

Figure 9. Temporal evolution of INU (INU > 1.5 SD), the volcanic eruptions and the standardized anomalies of EOF1, $\delta^{18} \mathrm{O},{ }^{10} \mathrm{Be}$ and sunspots for the period 1800-2009. All series are plotted as normalized values smoothed with an 11-year low-pass Gaussian filter, except the sunspot number record smoothed with a 22-year filter. The volcanic eruptions and INU index are unsmoothed. Periods of high flood frequency are marked on the chart. Note that the $\delta^{18} \mathrm{O}$ and sunspot scales are reversed.

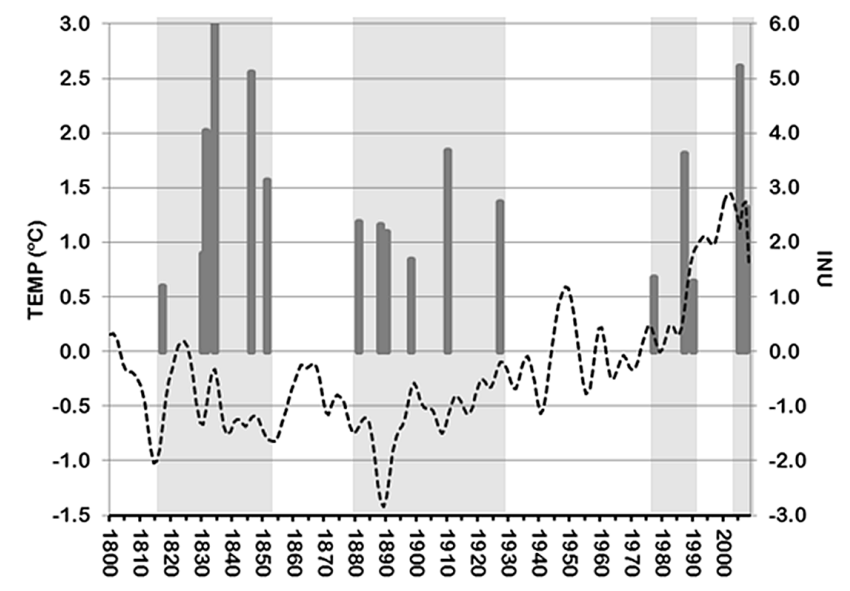

Figure 10. Temporal evolution of the standardized anomalies of INU (full line; INU > 1.5 SD) and the annual average temperature for Switzerland (dashed line) for the period 1800-2009. Both series are plotted as normalized values and temperature data are smoothed with an 11-year low-pass Gaussian filter.

flooding in Switzerland. For example, differences can be assumed between the two reanalysis data sets used in our study.

The 20CRP is based on the combination of surface and sea level pressure observations with a short-term forecast from an ensemble of integrations of an NCEP numerical weather prediction model. The ensemble Kalman filter technique is applied to produce an estimate of the complete state of the atmosphere (Compo et al., 2011).

In return, the monthly reconstructed SLP anomaly maps by Luterbacher et al. (2002) were developed using princi- pal component regression analysis based on the combination of early instrumental station series (pressure, temperature and precipitation) and documentary proxy data from Eurasian sites. The relationships were determined over the 1901-1960 calibration period and verified over 1961-1990. Under the assumption of stationarity in the statistical relationships, a transfer function derived over the 1901-1990 period was used to reconstruct the 500-year large-scale SLP fields (Luterbacher et al., 2002). Three principal difficulties can emerge in the reconstructed SLP maps: (1) the stationary assumption, (2) no observations over the sea (Küttel et al., 2009) and (3) statistical reconstructions are not necessarily related to physical phenomena.

1. In respect to the problem of stationary assumption, we emphasize that meaningful monthly reconstructions were available from around 1700 onwards, when station pressure series became available (Luterbacher et al., 2002). Furthermore, the uncertainty is lower after 1780 when meteorological observations were conducted (early instrumental period). For instance, the Meteorological Society of the Palatinate performed a catalogue of weather data (including pressure) for the period 1781-1792. These data were recorded by weather observers in 18 countries on both sides of the North Atlantic realm. Moreover, the number of predictors for the transfer function used in our reconstructed period (1800-2009) is around 50 in 1800 and approximately 100 in 1871 (more information: Fig. 1, p. 548 in Luterbacher et al., 2002). 
2. In contrast to the lower number of observations over the Atlantic Ocean, the reconstruction skill is good over western Europe. Küttel et al. (2009) suggest that this fact might be attributed to the inclusion of the western Baltic sea-ice index (Koslowski and Glaser, 1999) and the reconstructed precipitation from Andalusia by Rodrigo et al. (1999). These indices contribute very valuable information to the reconstruction of the entire area (Luterbacher et al. 2002).

3. Finally, physical interpretation from statistical artefacts can be controversial because climate is characterized by non-linearity and high dimensionality. Consequently, the statistical relationships are not necessarily indicative of the understanding of any physical mechanisms involved (Switanek and Troch, 2011).

The summer climate in western Europe can be synthesized by the EOF1 and we have identified a qualitative relationship between this pattern and the summer flood damage index INU (Sect. 3.4). Figure 9 shows that the second, third and fourth clusters of major floods in Switzerland coincide mostly with positive phases of EOF1, whereas the first flood cluster is not in phase with this atmospheric variability pattern. However, we suggest that the origin of the flood clusters might be attributed to the location of the atmospheric action centres during the positive (or negative) phase. The variability of the EOF1 pattern is associated with changes in the storm track of the North Atlantic-European sector. Positive (negative) values of EOF1 are related to the northward (or southward) shift of the storms and thus they become stronger over Iceland and the Norwegian Sea during a positive phase and weaken towards the south. This pattern generates dry, warm weather, especially in central and western Europe due to strong anticyclonic conditions (Folland et al., 2009). In southern Europe, the climate becomes more humid during these positive phases (Bladé et al., 2011). This atmospheric dynamics is illustrated in Fig. 6. We should emphasize that negative anomalies are observed in lower and middle atmospheric levels over the Mediterranean area. Switzerland lies on the northern boundary of this negative domain. This pattern promotes atmospheric instability in these areas and leads to positive precipitation anomalies. The enhanced precipitation is related to the presence of a strong upper level trough over the south-west of the Iberian Peninsula and the Mediterranean area that generates a cooling of the air in middle atmospheric levels and an increased potential for instability. Thus, EOF1 acts as a major control of climate variability during the high summer, not only in north-western Europe, but also in southern areas (Bladé et al., 2011). In this sense, this explains the qualitative link between the high summer largescale variability pattern and the frequency of major flooding in Switzerland. Additionally, the analysis of the different categories of the INU in relation to EOF1 (Table 1) shows that the positive phase of the pattern explains large impact flood events (INU > 5 SD; 4 of 33 episodes), but only part of the variability of the signal of INU ( 20 of 33 events). By contrast, the negative phase of EOF1 is associated with the remaining 11 events.

Based on the relationship between the North Atlantic dynamics and the INU index, two patterns might be proposed to explain the flooding in Swiss catchments since 1800.

The first flood pattern is associated with positive EOF1 phases (mean values vary between 0.04 and 0.45 ; Table 1; see Fig. 11). The INU > 5 SD category includes the four most catastrophic floods that have affected Switzerland in the last 200 years: 1831, 1834, 1846 and 2005. These events occurred during periods of low solar activity (positive values of ${ }^{10} \mathrm{Be}$ ) and, with the exception of the 2005 flood, during episodes of cold climate pulses in Greenland (negative values of $\delta^{18} \mathrm{O}$ ) and in the north-western Alps (temperature anomalies; Figs. 9 and 10). During these cold pulses the accumulation of snow and ice in the headwaters is significant, increasing the flood risk during warm years when melting processes contribute markedly to summer discharge. This flood pattern occurs in years, dominated by positive EOF1 phases when depressions are usually associated with the Atlantic cyclones that become more intense over the Mediterranean Sea, and follow a north-east to north-northeast track over the Alps (Blöschl et al., 2013). This path is known as $\mathrm{Vb}$ (van Bebber, 1891) and produces long-lasting, intense rainfall due to (1) the high water vapour content from the Mediterranean, (2) the orographic uplift of air masses and (3) the reinforcement suffered by negative anomalies of temperature and geopotential height that occurs at the lower and middle levels of the atmosphere. The most affected regions in Switzerland are regions 2 (western part of the northern flank of the Alps), 3 (Grisons plus southern flank of the Alps) and 5 (eastern part of the northern flank of the Alps); this accounts for $70 \%$ of the total of floods with INU > 2.5 and EOF1 in the positive phase (see Fig. 11). Similar findings have been reported by Grebner (1997) and Pfister (1999). They report that this atmospheric configuration causes catastrophic floods, especially in the greater Alpine region. Mudelsee et al. (2004) applied a point-wise biserial correlation coefficient between the flood events and sea level pressure and the $500 \mathrm{hPa}$ geopotential height for the summer flooding of the river Oder and Elbe in eastern central Europe, obtaining a pattern that is very similar to the large-scale atmospheric variability mode of positive EOF1 proposed herein. Müller and Kaspar (2011) obtained similar results for the summer floods in the Mura and Drava (south-eastern Alps) catchments, typical transboundary rivers of the eastern slopes of the Alps. The floods in these rivers were frequently connected with moisture fluxes from the east or the north at the $850 \mathrm{hPa}$ level. This configuration is associated with cyclones that are intensified over the Mediterranean Sea that affect central Europe as they move to the north-east along the $\mathrm{Vb}$ track. These results are also in agreement with the findings reported by SchmockerFackel and Naef (2010b), to the effect that the periods of high flood frequency in Switzerland are in phase with the sum- 
A)

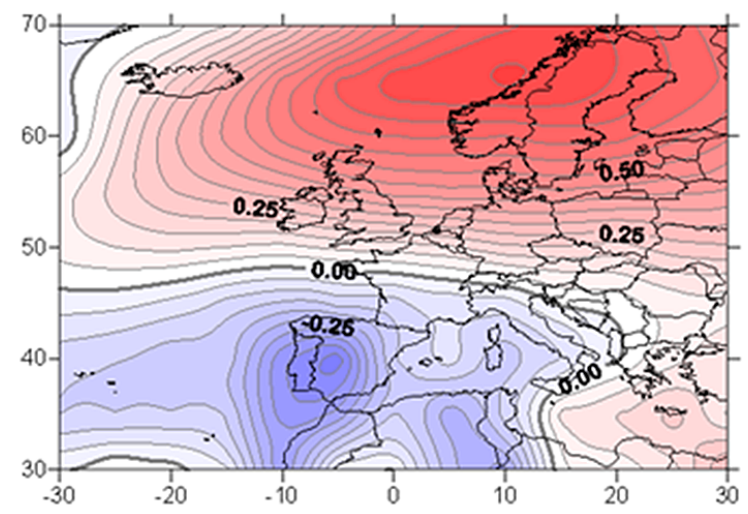

B)

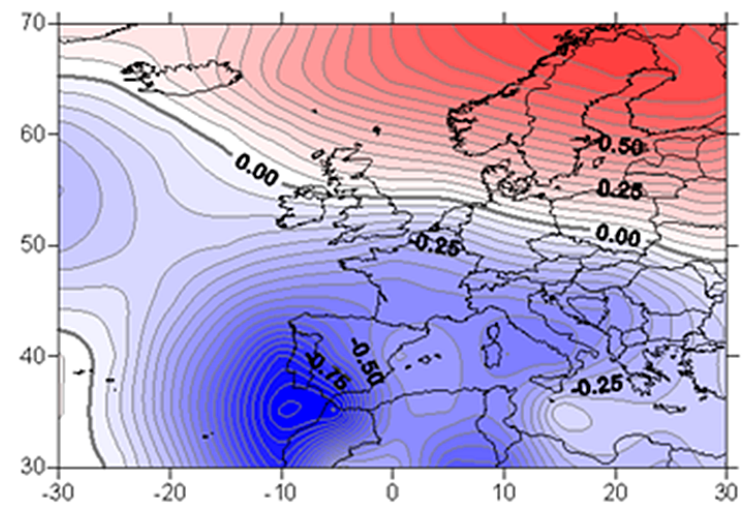

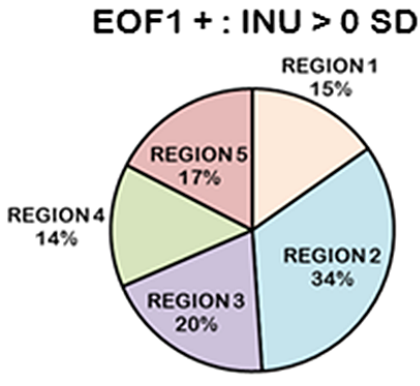

EOF1 $+:$ INU $>2.5$ SD

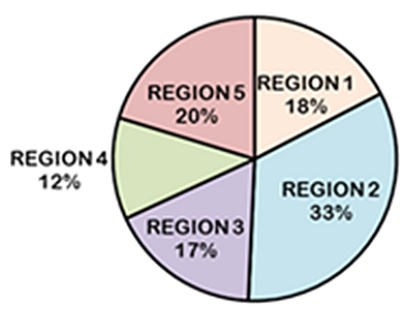

Figure 11. (a) Left: composites of monthly EMSLP extracted from 20CRP plus the Luterbacher reanalysis grids of the years with EOF1 in the positive phase and INU $>0$. The units are expressed in hPa. Red (blue) contours show positive (negative) anomalies. Right: number of floods in percentage by region. (b) is as (a) but for the years with INU > 2.5 SD. Region 1 encompasses Valais and western cantons, region 2 the western part of the northern slope of the Alps and the Swiss Plateau, region 3: Grisons plus the southern flank of the Alps, region 4 eastern Jura and the Swiss Plateau and region 5 encompasses the eastern part of the northern flank of the Alps.

mer floods of the Czech Republic (Brázdil et al., 2006), Italy (Camuffo and Enzi, 1996) and the eastern half of the Iberian Peninsula (Barriendos and Rodrigo, 2006), while the relationship is not so significant when compared with the flood occurrences observed in Germany (Glaser and Stangl, 2004).

The second flood pattern is determined by INU values linked to periods of low solar activity (positive values of ${ }^{10} \mathrm{Be}$ ) and episodes that are climatically cold (negative values of $\delta^{18} \mathrm{O}$ ), but unlike the first pattern, the EOF1 is in the negative phase. The number of years related to INU $>0$ is less than the pattern described above (13 of 33 events) and it is noteworthy that there are no EOF1 negative values for the category of INU $>5$. The synoptic configurations related to this large-scale atmospheric variability mode (Fig. 12) are characterized by cold fronts originating over the Atlantic, tracing a north-west to south-east path, funnelled by a low located at the latitude of Scandinavia and a high over the Atlantic Ocean. This configuration is very similar to that of the synoptic patterns defined by Jacobeit et al. (2006) and which are associated with the large summer floods in eight central European catchments (Rhine, Main, Mosel, Danube, Weser, Elbe, Spree and Oder). The persistence of this situation pro- duces significant rainfall over Switzerland and, consequently, floods that can have a considerably detrimental impact on the territory, its property and people (Pfister, 1999). The most affected regions in Switzerland are regions 2 (western part of the northern flank of the Alps) and 4 (eastern Jura mountains and Swiss Plateau); this accounts for $62 \%$ of the total of floods with INU > 2.5 and EOF1 in the negative phase (see Fig. 12).

Thus, the EOF1 defines the sensitivity of the Swiss river systems to extreme hydrological events controlled by the atmospheric processes operating in the Mediterranean area (disturbance over the gulfs of Genoa and Venice) and in the North Atlantic (cold fronts channelled between the Scandinavian low and the Atlantic anticyclone). Finally, the series shows differences and changes in the temporal and spatial distribution of floods numbers (see Fig. 8) and related phases of EOF1 (see Figs. 11 and 12). We have evidence that the positive phase of EOF1 strongly influences the floods in central, eastern and southern Switzerland, while the negative phase affects the central, western and northern Switzerland. From Fig. 8, we can infer a spatial flood pattern for the late pulses of the Little Ice Age (Phase A, cool period) which 
A)

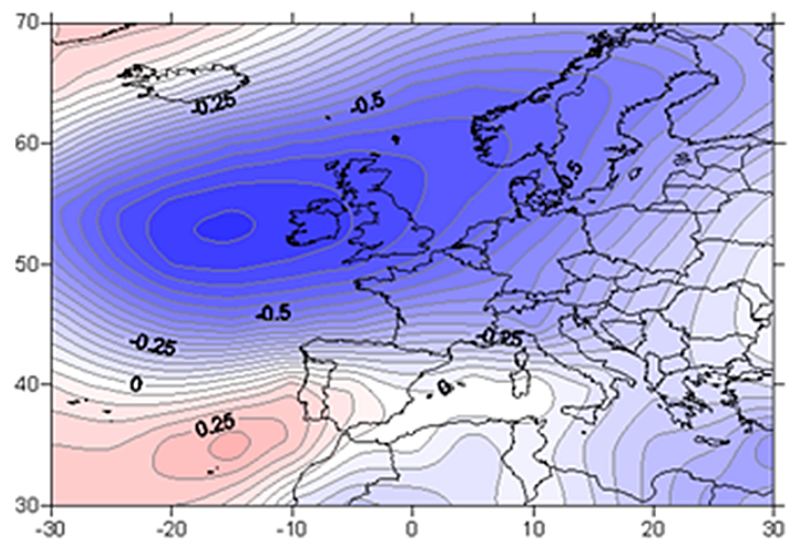

B)

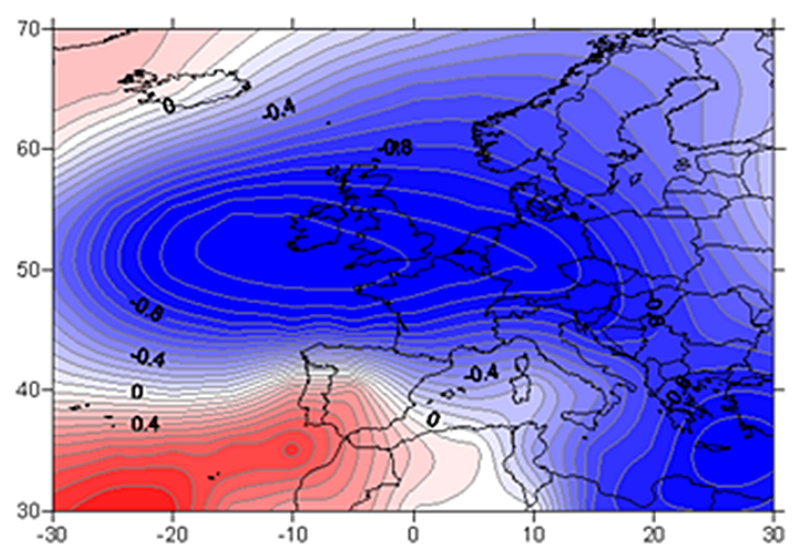

EOF1 - : INU > 0 SD

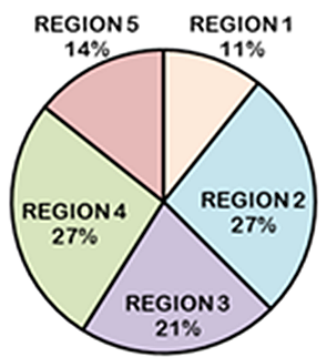

EOF1 - : INU > 2.5 SD

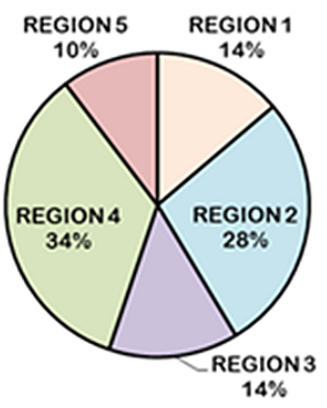

Figure 12. As in Fig. 11 but for EOF1 negative phase. Region 1 encompasses Valais and western cantons, region 2 the western part of the northern slope of the Alps and the Swiss Plateau, region 3 Grisons plus the southern flank of the Alps, region 4 eastern Jura and the Swiss Plateau and region 5 encompasses the eastern part of the northern flank of the Alps.

mainly affects the northern and western part of Switzerland, while a second pattern influences the central and southern part during the last 4 decades of the period of study (Phase B, warm period). From this spatial distribution of floods, it is possible to identify a change of the atmospheric patterns that affects the frequencies of floods in Switzerland during the last 200 years: the EOF1 persists in the negative phase during the last cool pulses of the Little Ice Age (1817-1851 and 1881-1927 flood clusters), whereas the positive phases of EOF1 prevail during the warmer climate of the last 4 decades (flood clusters from 1977 to present). These findings are consistent with the trend of the EOF1 time series for the period 1800-2009 (see Fig. 6; Mann-Kendall trend test shows a significant and positive trend at a $95 \%$ confidence level). Based on the obtained results, future research should focus on how these atmospheric mechanisms control the onset of high-frequency periods of major flooding.

\section{Conclusions}

We presented a new flood damage index (INU) for Switzerland between 1800 and 2009, exploring the influence of ex- ternal forcings on flood frequencies and with the principal low-frequency atmospheric variability mode in summer (EOF1). Our major findings are presented below.

1. The hydro-climatic regionalization shows two patterns of spatial variability related to the principal moisture sources that affect Switzerland: Mediterranean and Atlantic humidity supplies. The first pattern is defined by a north-south cross section, while the second is linked to a west-east cross section. Taking these findings into account, the final classification presents five different regions that are consistent with other hydrographic classifications developed for Switzerland.

2. Despite regional climate differences within Switzerland, INU provides evidence that the 1817-1851, 18811927, 1977-1990 and 2005-present flood clusters are mostly in phase with palaeoclimate proxies and North Atlantic dynamics. Moreover, these periods coincide with those identified in a range of studies concerned with the occurrence of floods in Switzerland and in the other river systems of eastern central Europe. The 20th century flood gap identified by the INU, reflecting the 
absence of extreme weather conditions, contrasts with the higher flood frequency of the last 3 to 4 decades, which has contributed to the increased perception of flood events.

3. The cross-spectral analysis shows that the periodicities detected in the coherency and phase spectra of 11 (Schwabe cycle) and 104 years (Gleissberg cycle) are related to a high flooding frequency and solar activity minima, whereas the 22-year cyclicity detected (Hale cycle) is associated with solar activity maxima and a decrease in flood frequency. We suggest that changes in large-scale atmospheric variability (autogenic forcing) and solar activity (exogenic forcing) influence the occurrence of flood periods, although there is no general consensus as to how solar forcing has affected climate and flood dynamics in recent centuries.

4. The analysis of the modes of low-frequency atmospheric variability based on the standardized daily anomalies of sea level pressure shows that Switzerland is located close to the border of the principal mode of summer atmospheric variability (EOF1) that is controlled by North Atlantic dynamics. Small shifts of this system border may introduce atmospherical instability over the Swiss river catchments. Very severe and catastrophic flood episodes are influenced strongly by positive (mostly central and southern basins) and negative EOF1 (mostly the northern basins) mode, which include a range of synoptic patterns that generate severe floods. Finally we can state that the EOF1 in the negative phase controlled notably major floods during the last stages of the Little Ice Age (1817-1851 and 18811927 flood clusters), while the positive EOF1 prevailed during the last 4 warmer decades (flood clusters from 1977 to present).

Acknowledgements. The work of the Fluvalps Research Group (PaleoRisk; 2014 SGR 507) was funded by the Catalan Institution for Research and Advanced Studies (ICREA Academia 2011) and the Spanish Ministry of Education and Science (CGL2009-0111; CGL2013-43716-R). The flood damage data for the period 19722010 were provided by the Swiss Federal Institute for Forest, Snow and Landscape Research WSL (Swiss flood and landslide damage database). The authors wish to thank the SIDC team, the World Data Center for the Sunspot Index of the Royal Observatory of Belgium and the ALP-IMP project for the Annual Temperature of Switzerland. The authors are also grateful to the DOE INCITE program, the Office of Biological and Environmental Research (BER) and to the NOAA, which provided the Twentieth Century Reanalysis Project data set. The authors thank Nadine Hilker for preparation of flood damage data (1972-2009) and Norina Andres for her helpful comments. We thank the two anonymous referees for useful comments and suggestions on improving the manuscript.

\section{References}

Abreu, J. A., Beer, J., Steinhilber, F., Christl, M., and Kubik, P. W.: ${ }^{10} \mathrm{Be}$ in Ice Cores and $14 \mathrm{C}$ in Tree Rings: Separation of Production and Climate Effects, Space Sci. Rev., 176, 343-349, 2012.

ALP-IMP: Multi-centennial climate variability in the Alps based on Instrumental data, Model simulations and Proxy data, Final report for RTD-project ALP-IMP (EVK-CT-2002-00148), 2006.

Annually resolved ${ }^{10} \mathrm{Be}$ data (Berggren et al., 2009) are available from Greenland, available at: ftp://ftp.ncdc.noaa.gov/pub/data/ paleo/icecore/greenland/summit/ngrip/ngrip-10be.txt, last access: 12 September 2013.

Annually resolved $\delta^{18} \mathrm{O}$ data (Stuiver and Grootes, 2000), available at: http://depts.washington.edu/qil/datasets/gisp2_main.html, last access: 21 January 2013.

Baldwin, M. P., Gray, L. J., Dunkerton, T. J., Hamilton, K., Haynes, P. H., Randel, W. J, Holton, J. R., Alexander, M. J., Hirota, I., Horinouchi, T., Jones, D. B. A., Kinnersley, J. S., Marquardt C., Sato, K., and Takahashi, M.: The Quasi-Biennial Oscillation, Rev. Geophys., 39, 179-229, 2001.

Barriendos, M. and Rodrigo, F. S.: Study of historical flood events on Spanish rivers using documentary data, Hydrol. Sci. J., 51, 765-783, 2006.

Beer, J., Mende, W., and Stellmacher, R.: The role of the sun in climate forcing, Quaternary Sci. Rev., 19, 403-415, 2000.

Benito, G., Díez-Herrero, A., and de Villalta, M.: Magnitude and frequency of flooding in the Tagus River (Central Spain) over the last millennium, Clim. Change, 58, 171-192, 2003.

Benito, G., Ouarda, T. B. M. J., and Bárdossy, A.: Applications of Palaeoflood hydrology and historical data in flood risk analysis, in: Palaeofloods, historical data and climate variability, edited by: Benito, G., Ouarda, T. B. M. J., and Bárdossy, A., J. Hydrol., 313, 1-2, 2005.

Berggren, A. M., Beer, J., Possnert, G., Aldahan, A., Kubik, P., Christl, M., Johnsen, S. J., Abreu, J., and Vinther, B. M.: A 600year annual ${ }^{10} \mathrm{Be}$ record from the NGRIP ice core, Greenland, Geophys. Res. Lett., 36, L11801, doi:10.1029/2009GL038004, 2009

Bladé, I., Liebmann, B., Fortuny, D., and van Oldenborgh, G. J.: Observed and simulated impacts of the summer NAO in Europe: Implications for projected drying in the Mediterranean region, Clim. Dynam., 39, 709-727, 2011.

Boch, R. and Spötl, C.: The origin of lamination in stalagmites from Katerloch Cave, Austria: Towards a seasonality proxy, PAGES News, 16, 21-22, 2008.

Borgmark, A.: Holocene climate variability and periodicities in south-central Sweden, as interpreted from peat humification analysis, The Holocene, 15, 387-395, 2005.

Blöschl, G., Nester, T., Komma, J., Parajka, J., and Perdigão, R. A. P.: The June 2013 flood in the Upper Danube Basin, and comparisons with the 2002, 1954 and 1899 floods, Hydrol. Earth Syst. Sci., 17, 5197-5212, doi:10.5194/hess-17-5197-2013, 2013.

Brázdil, R., Dobrovolný, P., Kakos, V., and Kotyza, O.: Historical and recent floods in the Czech Republic. Causes, seasonality, trends, impacts, in: Floods risk management. Hazards, vulnerability and mitigation measures, edited by: Schanze, J., Zeman, E., and Marsalek, J., NATO Science Series, Springer-Verlag, Berlin, 247-259, 2006.

Edited by: A. Kiss 
Briffa, K. R.: Annual climate variability in the Holocene: interpreting the message of ancient trees, Quaternary Sci. Rev., 19, 87$105,2000$.

Büntgen, U., Frank, D., Nievergelt, D., and Esper, J.: Summer temperature variations in the European Alps, A.D. 755-2004, J. Climate, 19, 5606-5623, 2006.

Burger, L.: Informationsbeschaffung bei Hochwassersituationen Dokumentation der grössten überregionalen Hochwasserkatastrophen der letzten 200 Jahre in der Schweiz, Diplomarbeit, Bern, 2008.

Camuffo, D. and Enzi, S.: The analysis of two bi-millennial series. Tiber and Po river floods, in: Climate variations and forcing mechanisms of the last 2000 years, edited by: Jones, P. D., Bradley, R. S., and Jourzel, J., NATO Science Series, SpringerVerlag, Berlin 141, 433-450, 1996.

Casty, C., Wanner, H., Luterbacher, J., Esper, J., and Böhm, R.: Temperature and precipitation variability in the European Alps since 1500, Int. J. Climatol., 25, 1855-1880, 2005.

Cattell, R. B.: The scree test for the number of the factors, Multivar. Behav. Res., 1, 245-276, 1966

Compo, G. P., Whitaker, J. S., Sardeshmukh, P. D., Matsui, N., Allan, R. J., Yin, X., Gleason, B. E., Vose, R. S., Rutledge, G., Bessemoulin, P., Brönnimann, S., Brunet, M., Crouthamel, R. I., Grant, A. N., Groisman, P. Y., Jones, P. D., Kruk, M., Kruger, A. C., Marshall, G. J., Maugeri, M., Mok, H. Y., Nordli, Ø., Ross, T. F., Trigo, R. M., Wang, X. L., Woodruff, S. D., and Worley, S. J.: The Twentieth Century Reanalysis Project, Q. J. Roy. Meteor. Soc., 137, 1-28, 2011.

Cook, E. R. and Stockton, C. W.: A new assessment of possible solar and lunar forcing of the bidecadal drought rhythm in the western United States, J. Climate, 10, 1343-1356, 1997.

Folland, C. K., Knight, J., Linderholm, H. W., Fereday, D., Ineson, S., and Hurrell, J. W.: The summer North Atlantic Oscillation: past, present, and future, J. Climate, 22, 1082-1103, 2009.

Frei, C., Davis, H. C., Gurtz, J., and Schär, C.: Climate dynamics and extreme precipitation and flood events in central Europe, Intergraded Assessment, 1, 281-299, 2001.

Gao, Ch., Robock, A., and Ammann, C.: Volcanic forcing of climate over the past 1500 years: An improved ice-core-based index for climate models, J. Geophys. Res., 113, D23111, doi:10.1029/2008JD010239, 2008.

Gees, A.: Analyse historischer und seltener Hochwasser in der Schweiz. Bedeutung für das Bemessungshochwasser, Geographica Bernensia G53, Bern, Switzerland, 1997.

Glaser, R. and Stangl, H.: Climate and floods in Central Europe since AD 1000: Data, methods, results and consequences, Surv. Geophys., 25, 485-510, 2004.

Glaser, R., Riemann, D., Schönbein, J., Barriendos, M., Brazdil, R., Bertolin, C., Camuffo, D., Deutsch, M., Dobrovolný, P., van Engelen, A., Enzi, S., Halíčková. M., Koenig, S. J., Kotyza, O., Limanówka, D., Macková, J., Sghedoni, M., Martin, B., and Himmelsbach, I.: The variability of European floods since AD1500, Clim. Change, 101, 235-256, 2010.

Glur, L., With, S., Büntgen, U., Gili, A., Haug, G., Schär, Ch., Beer, J., and Anselmetti, F.: Frequent floods in the Europeans Alps coincide with cooler periods of the past 2500 years, Scientific Reports, 3, 2770, doi:10.1038/srep02770, 2013.

Gray, L. J., Beer, J., Geller, M., Haigh, J. D., Lockwood, M., Matthes, K., Cubasch, U., Fleitmann, D., Harrison, G., Hood,
L., Luterbacher, J., Meehl, G. A., Shindell, D., van Geel B., and White W.: Solar influences on climate, Rev. Geophys., 48, RG4001, doi:10.1029/2009RG000282, 2010

Grebner, D.: Meteorologische Verhältnisse und Starkniederschläge im Alpenraum. In: Recherche dans le domaine des barrages, Crues extrêmes, Laboratoire de constructions hydrauliques, Département d'ingénierie civil. Séminaire à l'Ecole Polytechnique Fédérale de Lausanne, Communication 5, 1-6, 1997.

Hächler-Tanner, S.: Hochwasserereignisse im Schweizerischen Alpenraum seit dem Spätmittelalter, Raum-zeitliche Rekonstruktion und gesellschaftliche Reaktionen, Lizenziatsarbeit in Schweizergeschichte, Historisches Institut der Uni Bern, 1991.

Hair, J. F., Anderson, R. E., Tatham, R. L., and Black, W. C.: Multivariate Data Analysis, Prentice-Hall, Inc., Upper Saddle River, New Jersey, 1998.

Hilker, N., Badoux, A., and Hegg, C.: The Swiss flood and landslide damage database 1972-2007, Nat. Hazards Earth Syst. Sci., 9, 913-925, doi:10.5194/nhess-9-913-2009, 2009.

Hirschboeck, K. K.: Flood hydroclimatology, in: Flood Geomorphology, edited by: Baker, V. R., Kochel, R. C., and Patton, C., John Wiley, 27-49, 1988.

Holzhauser, H., Magny, M., and Zumbühl, H. J.: Glacier and lakelevel variations in west-central Europe over the last 3500 years, The Holocene, 15, 789-801, 2005.

Hurrell, J. W., Kushnir, Y., Ottersen, G., Visbeck, M.: An overview of the North Atlantic Oscillation, in: The North Atlantic Oscillation: climatic significance and environmental impact, edited by: Hurrell, J. W., Kushnir, Y., Ottersen, G., and Visbeck, M., Geophysical Monograph Series, 134, 1-35, 2003.

Jacobeit, J., Philipp, A., and Nonnenmacher, M.: Atmospheric circulation dynamics linked with prominent discharge events in Central Europe, Hydrolog. Sci. J., 51, 946-965, 2006.

Kaiser, H. F.: An index of factorial simplicity, Psychometrika, 39, 31-36, 1974.

Kalnay, E., Kanamitsu, M., Kistler, R., Collins, W., Deaven, D., Gandin, L., Iredell, M., Saha, S., White, G., Woollen, J., Zhu, Y., Chelliah, M., Ebisuzaki, W., Higgins, W., Janowiak, J., Mo, K.C., Ropelewski, C., Wang, J., Leetmaa, A., Reynolds, R., Jenne, R., and Joseph, D.: The NCEP/NCAR 40-year reanalysis project, B. Am. Meteorol. Soc., 77, 437-471, 1996.

Kirchhofer, W.: Climatological atlas of Switzerland. Meteoswiss, Federal Office of Topography swisstopo, 2000.

Knox, J. C.: Sensitivity of modern and Holocene floods to climate change, Quaternary Sci. Rev., 19, 439-457, 2000.

Koslowski, G. and Glaser, R.: Variations in reconstructed ice winter severity in the western Baltic from 1501 to 1995, and their implications for the North Atlantic Oscillation, Clim. Change, 41, 175-191, 1999.

Küttel, M., Xoplaki, E., Gallego, D., Luterbacher, J., GarcíaHerrera, R., Allan, R., Barriendos, M., Jones, P. D., Wheeler, D., and Wanner, H.: The importance of ship log data: reconstructing North Atlantic, European and Mediterranean sea level pressure fields back to 1750 , Clim. Dynam., 34, 1115-1128, doi:10.1007/s00382-009-0577-9, 2009.

Lehmann, C. and Naef, F.: Die Größe der extremen Hochwasser der Lütschine, Tiefbauamt des Kanton Bern, Bern, 2003.

Luterbacher, J., Xoplaki, E., Dietrich, D., Rickli, R., Jacobeit, J., Beck, C., Gyalistras, D., Schmutz, C., and Wanner, H.: Reconstruction of sea level pressure fields over the Eastern North At- 
lantic and Europe back to 1500 , Clim. Dynam., 18, 545-561, 2002.

Luterbacher, J., Dietrich, D., Xoplaki, E., Grosjean, M., and Wanner, H.: European seasonal and annual temperature variability, trends, and extremes since 1500, Science, 303, 1499-1503, 2004.

Magny, M., Bégeot, C., Guiot, J., and Peyron, O.: Contrasting patterns of hydrological changes in Europe in response to Holocene climate cooling phases, Quaternary Sci. Rev., 22, 1589-1596, 2003.

Mudelsee, M., Börngen, M., Tetzlaff, G., and Grünewald, U.: Extreme floods in central Europe over the past 500 years: Role of cyclone pathway "Zugstrasse Vb", J. Geophys. Res.-Atmos., 109, 2156-2202, 2004.

Müller, M. and Kaspar, M.: Association between anomalies of moisture flux and extreme runoff events in the southeastern Alps, Nat. Hazards Earth Syst. Sci., 11, 915-920, doi:10.5194/nhess-11-915-2011, 2011.

Ortega, J. A. and Garzón, G.: A contribution to improved flood magnitude estimation in base of palaeoflood record and climatic implications - Guadiana River (Iberian Peninsula), Nat. Hazards Earth Syst. Sci., 9, 229-239, doi:10.5194/nhess-9-2292009, 2009.

Percival, D. B. and Walden, A. T.: Spectral Analysis for physical Applications, Cambridge University Press, Cambridge, 1993.

Peristykh, A. N. and Damon, P. E.: Persistence of the Gleissberg 88-year solar cycle over the last $\sim 12,000$ years: Evidence from cosmogenic isotopes, J. Geophys. Res., 108, 1003, doi:10.1029/2002ja009390, 2003.

Pfister, C.: Wetternachhersage: 500 Jahre Klimavariationen und Naturkatastrophen, Paul Haupt Verlag, Bern, 1999.

Pfister, C. and Hächler S.: Überschwemmungskatastrophen im Schweizer Alpenraum seit dem Spätmittelalter. Raum-zeitliche Rekonstruktion von Schadenmustern auf der Basis historischer Queilen, Würzburger Geographische Arbeiten, 80, 127-148, 1991.

Reconstruction of Sea Level Pressure fields over the eastern North Atlantic and Europe back to 1500 (Luterbacher et al., 2002) dataset, available at: http://www.ncdc.noaa.gov/ paleo/pubs/luterbacher2002/luterbacher2002.html, last access: 16 September 2011.

Rodrigo, F. S., Esteban-Parra, M. J., Pozo-Vazquez, D., and CastroDiez, Y.: A 500-year precipitation record in Southern Spain, Int. J. Climatol., 19, 1233-1253, 1999.

Rogers, M. L., Richards, M. T., and Richards, D. St. P.: Long-term variability in the length of the solar cycle, Astrophysics: arXiv: astro-ph/0606426v3, p. 15, 2006.

Röthlisberger, G.: Chronik der Unwetterschäden in der Schweiz, Berichte der Eidge-nössischen Forschungsanstalt für Wald, Schnee und Landschaft, 330, 122 pp., 1991.

Schmocker-Fackel, P. and Naef, F.: More frequent flooding? Changes in flood frequency in Switzerland since 1850, J. Hydrol., 381, 1-8, 2010a.

Schmocker-Fackel, P. and Naef, F.: Changes in flood frequencies in Switzerland since 1500, Hydrol. Earth Syst. Sci., 14, 1581-1594, doi:10.5194/hess-14-1581-2010, 2010b.

Schulte, L., Julià, R., Oliva, M., Burjachs, F., Veit, H., and Carvalho, F.: Sensitivity of Alpine fluvial environments in the Swiss Alps to climate forcing during the Late Holocene. Sediment Dy- namics in Changing Environments, International Association of Hydrological Sciences Publications, 325, 367-374, 2008.

Schulte, L., Veit, H., Burjachs, F., and Julià, R.: Lütschine fan delta response to climate variability and land use in the Bernese Alps during the last 2400 years, Geomorphology, 108, 107-121, 2009a.

Schulte, L., Julià, R., Veit, H., and Carvalho, F.: Do high resolution fan delta records provide a useful tool for hazard assessment in mountain regions?, International Journal of Climate Change Strategies and Management, 1, 197-210, 2009b.

Schulte, L., Carvalho, F., Peña, J.C., Baró, M., Julià, R., Burjachs F., Lomax J., Villanueva, I., Rubio, P., and Veit, H.: Trying to understand mountain flood dynamics from multiproxy data: a 4600year high resolution record from the Swiss Alps, Quatern. Int., 439, 279-280, 2012.

Schulte, L., Peña, J.C., Julià, R., Carvalho, F., Llorca, J., Losada, J., Burjachs, F., Schmidt, T., Rubio, P., and Veit, H.: Climate forcing of paleofloods in the Swiss Alps, in: Avances de la Geomorfología en España 2012-2014, edited by: Schnabel, S. and Gómez Gutiérrez, A., XIII Reunión Nacional de Geomorfología, 143-146, 2014.

Schulte, L., Peña, J. C., Carvalho, F., Schmidt, T., Julià, R., Llorca, J., and Veit, H.: A 2600-year history of floods in the Bernese Alps, Switzerland: frequencies, mechanisms and climate forcing, Hydrol. Earth Syst. Sci., 19, 3047-3072, doi:10.5194/hess-193047-2015, 2015.

Schulz, M. and Statteger, K.: SPECTRUM: Spectral analysis of unevenly spaced paleoclimatic time series, Comput. Geosci., 23, 929-945, 1997.

Schulz, M., Mudelsee, M., and REDFIT: Estimating red-noise spectra directly from unevenly spaced paleoclimatic time series, Comput. Geosci., 28, 421-426, 2002.

Shackleton, N. J.: The 100,000-year ice-age cycle identified and found to lag temperature, carbon dioxide, and orbital eccentricity, Science, 289, 1897-1902, 2000.

Siegel, A. F.: The noncentral chi-squared distribution with zero degrees of freedom and testing for uniformity, Biometrika, 66, 381386, 1979.

Solanki, S. K. and Fligge, M.: Reconstruction of past solar irradiance, Space Sci. Rev., 94, 127-138, 2000.

Stuiver, M. and Grootes, P. M.: GISP2 Oxygen Isotope Ratios, Quaternary Res., 53, 277-284, 2000.

Stuiver, M., Braziunas, T. F., Grootes, P. M., and Zielinski, G. A.: Is there evidence for solar forcing of climate in the GISP2 Oxygen Isotope record?, Quaternary Res., 48, 259-266, 1997.

Switaneck, M. B. and Troch, P. A.: Decadal prediction of Colorado River streamflow anomalies using oceanatmosphere teleconnections, Geophys. Res. Lett., 38, L23404, doi:10.1029/2011GL049644, 2011.

The annual average sunspot for the period between 1700 and 2011, available at: http://www.sidc.be/sunspot-data/, last access: 7 October 2013.

The Annual Temperature of Switzerland (ALP-IMP, 2006), available at: http://www.zamg.ac.at/ALP-IMP/, last access: 9 October 2013.

Tinner, W., Lotterb, A. F., Ammann, B., Conederac, M., Hubschmida, P., van Leeuwena, J. F. N., and Wehrlia, M.: Climatic change and contemporaneous land-use phases north and south of 
the Alps 2300 BC to 800 AD, Quaternary Sci. Rev., 22, 14471460, 2003.

Twentieth Century Reanalysis Project (Compo et al., 2011) dataset, available at: http://www.esrl.noaa.gov/psd/data/gridded/ data.20thC_ReanV2.html, last access: 5 July 2011.

van Bebber, W. J.: Die Zugstrassen der barometrischen Minima nach den Bahnenkarten der Deutschen Seewarte für denZeitraum von 1870-1890, Meteorol. Z., 8, 361-366, 1891.

Vaquero, J. M.: Solar signal in the number of floods recorded for the Tagus river basin over the last millennium, Clim. Change, 66, 23-26, 2004.

Versteegh, G. J. M.: Solar Forcing of Climate. 2: Evidence from the Past, Space Sci. Rev., 120, 243-286, 2005.

Vischer, D.: Die Geschichte des Hochwasserschutzes in Schweiz: von den Anfängen bis ins 19. Jahrhundert, Bundesamt für Wasser und Geologie, Bern, 2003.

Volcanic Eruptions for the Northern Hemisphere for the period 1800-2000, available at: http://climate.envsci.rutgers.edu/IVI2/, last access: 9 February 2015.

Vonmoos, M., Beer, J., and Muscheler, R.: Large variations in Holocene solar activity: Constraints from ${ }^{10} \mathrm{Be}$ in the Greenland Ice Core Project ice core, J. Geophys. Res.-Space, 111, A10105, doi:10.1029/2005JA011500, 2006.

Weingartner, R., Reist, T.: Gotthelfs "Wassernot im Emmental" Hydrologische Simulation des Extremhochwassers vom 13. August 1837, in: Katastrophen und ihre Bewältigung - Perspektiven und Positionen, edited by: Pfister, Ch. and Summermatter, S., Berner Universitätsschriften, Band 49, Haupt-Verlag, 21-41, 2004.
Wetter, O., Pfister, Ch., Weingartner, R., Luterbacher, J., Reist, T., and Trösch, J.: The largest floods in the High Rhine basin since 1268 assessed from documentary and instrumental evidence, Hydrol. Sci. J., 56, 733-758, 2011.

Wilhelm, B., Arnaud, F., Sabatier, P., Crouzet, Ch., Brisset, E., Chaumillion, E., Disnar, J. R., Guiter, F., Malet, E., Reyss, J. L., Tachikawa, K., Bard, E., and Delannoy, J. J.: 1400 years of extreme precipitation patterns over the Mediterranean French Alps and possible forcing mechanisms, Quaternary Res., 78, 1-12, 2012.

Wirth, S., Gilli, A., Simonneau, A., Ariztegui, D., Vannière, B., Glur, L., Chapron, E., Magny, M., and Anselmetti, F.: A 2000 year long seasonal record of floods in the southern European Alps, Geophys. Res. Lett., 40, 4025-4029, doi:10.1002/grl.50741, 2013a.

Wirth, S., Glur, L., Gilli, A., and Anselmetti, F.: Holocene flood frequency across the Central Alps - solar forcing and evidence for variations in North Atlantic atmospheric circulation, Quaternary Sci. Rev., 80, 112-128, 2013 b. 